02 Royal Netherlands Institute for Sea Research

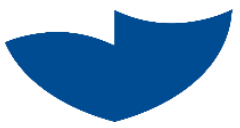

This is a postprint of:

Nauw, J., Haas, H. de \& Rehder, G. (2015). A review of oceanographic and meteorological controls on the North Sea circulation and hydrodynamics with a view to the fate of North Sea methane from well site 22/4b and other seabed sources. Marine and Petroleum Geology, 68 (Part B), 789-805

Published version: $\underline{\mathrm{dx} . \text { doi.org/10.1016/..marpetgeo.2015.08.007 }}$

Link NIOZ Repository: $\underline{w w w . v l i z . b e / n l / i m i s ? m o d u l e=r e f \& r e f i d=249939 ~}$

[Article begins on next page]

The NIOZ Repository gives free access to the digital collection of the work of the Royal Netherlands Institute for Sea Research. This archive is managed according to the principles of the Open Access Movement, and the Open Archive Initiative. Each publication should be cited to its original source - please use the reference as presented.

When using parts of, or whole publications in your own work, permission from the author(s) or copyright holder(s) is always needed. 


\section{Bubble momentum plume as a possible mechanism for an early breakdown of the seasonal stratification in the northern North Sea}

Janine Nauw ${ }^{a}$, Peter Linke ${ }^{b}$ and I. Leifer ${ }^{c, d}$

a Royal Netherlands Institute for Sea Research, NIOZ, Texel, the Netherlands, Janine.Nauw@nioz.nl

b Helmholtz Centre for Ocean Research, GEOMAR, Kiel, Germany, plinke@geomar.de

c University of California, Santa Barbara, ira.s.leifer@gmail.com

d Bubbleology Research International, ira.leifer@bubbleology.com

\section{Abstract}

The presence of a seasonal thermocline likely plays a key role in restraining methane released from a seabed source in the deeper water column, thereby inhibiting exchange to the atmosphere. The bubble plume itself, however, generates an upward motion of fluid, e.g. upwelling and may thereby be partially responsible for an early breakdown of the seasonal thermocline. Measurements at site $22 / 4 \mathrm{~b}$, located at $\left(57^{\circ} 55^{\prime} \mathrm{N}, 1^{\circ} 38^{\prime} \mathrm{E}\right)$ in the UK Central North Sea, $200 \mathrm{~km}$ east of the Scottish mainland, where gas is still being released since a blow out in 1990, have been used to identify the generation of the seasonal thermocline, and thus, the depth of the upper mixed layer and its breakdown in autumn. Data derived from two landers, containing an Acoustic Doppler Current Profiler and a Conductivity Temperature Depth recorder, were used to determine the mixed layer depth and the breakdown of the thermocline. Mixing of upper layer fluid into the lower layer has been inferred from large amplitude variations in the near-bottom temperature.

The ADCPs estimate velocity profiles in four beam directions using Doppler shifted frequency from acoustic pings sent out and received by four different transducers in a specific configuration. Besides that, the intensity of the backscattered sound per transducer is also recorded. Bubbles from the nearby plume contaminate the signal during part of the tidal cycle, but in bubble free periods, the mixed layer depth can be estimated using the acoustic backscatter signal as local maxima. Results show that the thermocline broke down between mid-October and early November, several weeks earlier than the breakdown of the thermocline in nearby/comparable areas, likely caused by bubble-induced downwelling at the site. The early breakdown of the thermocline was accompanied by multiple occurrence of a strong jet-like structure, associated with the seasonal tidal mixing front. 


\section{Introduction}

\subsection{Geologic Marine Methane Importance}

Geologic marine seabed $\mathrm{CH}_{4}$ emission contributes significantly to the global atmospheric budget of the important greenhouse gas, $\mathrm{CH}_{4}$ (Etiope et al., 2008). However, there are significant uncertainties due to the complexity in its transport across the water column to the atmosphere (Leifer and Patro, 2002) and a paucity of measurements. One significant factor is the thermocline, which traps dissolved $\mathrm{CH}_{4}$ in deeper waters, where it largely is oxidized by microbes (Rehder et al., 1999; Scranton and McShane, 1991) minimizing its contribution to the atmospheric budget. Although, the thermocline is a barrier to upwards $\mathrm{CH}_{4}$ diffusion and vertical fluid motions, bubbles pass through it, while carrying their $\mathrm{CH}_{4}$ to upper waters, where it either is released directly to the atmosphere (e.g. Leifer et al., 2006) or indirectly by sea-air gas exchange (e.g. Schneider von Deimling et al., 2011; Clark et al., 2000). Based on timescale considerations, Rehder et al., 1999) proposed that the relevant process is the transport to the winter wave-mixed-layer, i.e., the deepest thermocline depth.

Marine $\mathrm{CH}_{4}$ emissions occur from all global coastal oceans from biogenic and thermogenic sources (Judd et al., 2002). The latter are associated with petroleum reservoirs, which often are under production. Petroleum basins under exploitation such as offshore California, in the Santa Barbara Channel (Hornafius et al., 1999), the Gulf of Mexico (Solomon et al., 2009) and the North Sea (Judd and Hovland, 2007) are well known for natural marine seepage, contributing to the regional atmospheric $\mathrm{CH}_{4}$ budget, particularly shallower seeps (Leifer and Patro, 2002). However, few long-term observations of shallow basin-wide emissions exist, although in cases like the Santa Barbara Channel, their contribution is significant on a local scale (Bradley, 2013).

Emissions associated with fossil fuel industrial activity, natural geologic emissions, and advection of terrestrial emissions contribute to elevated atmospheric $\mathrm{CH}_{4}$ concentrations over the North Sea (Judd, 2015; Vielstädte et al., 2015). The North Sea is an important petroleum production basin with estimated reserves in 2001 of 19.5 and 17 billion barrels for the UK and Norwegian sectors, respectively (Sem and Ellerman, 1999), providing $5.7 \%$ of global supply in 2005 (Nakhle, 2008).

At the $22 / 4 \mathrm{~b}$ site, a bubble megaplume $\left(>10^{6} \mathrm{Ld}^{-1}\right)$ is associated with a gas blowout in 1990 in the central North Sea $200 \mathrm{~km}$ from the Scottish mainland at $1.63^{\circ} \mathrm{E}, 57.92^{\circ} \mathrm{N}$ (Leifer and Judd, 2015), and has been the subject of studies for many years (Rehder et al., 1998; Rehder et al., 2004; Schneider von Deimling et al., 2007; Schneider von Deimling et al., 2015). This megaplume is by far the strongest bubble plume quantified to date (Leifer et al., 2015), emitting an estimated $90 \mathrm{~L} \mathrm{~s}^{-1}$ at 12 bar from a seabed crater with maximum depth of 120 $\mathrm{m}$, while exhibiting strong upwelling flows. Herein, we present nearly one-year long measurements of physical parameters, including velocity profiles, temperature and salinity concentrations, by a benthic lander deployed in the blowout crater and focus on the relationship and feedbacks between the strong seasonal thermocline and fluid motions associated with intense bubble plumes under the oceanographic conditions of the North Sea, such as tides and waves. 


\subsection{Circulation in the northern North Sea}

North Sea circulation is dominated by oscillatory motions on the semi-diurnal and spring-neap tidal frequencies based on the M2 and S2 components. Due to nonlinear interactions between the tidal components and topography, a residual circulation is driven in the same direction as the tidal wave, which enters the North Sea in the Northwest from the Atlantic and in the South through the English Channel and follows an anti-clockwise circulation (Nauw et al., 2015; Otto et al., 1990). At the $22 / 4 \mathrm{~b}$ site, the $M 2$ tidal current is $\left(u_{M 2}, v_{M 2}\right)=(0.04$, $0.23) \mathrm{m} / \mathrm{s}$ and the $\mathrm{S} 2$ tidal current is $\left(u_{\mathrm{s} 2}, v_{\mathrm{s} 2}\right)=(0.02,0.09) \mathrm{m} / \mathrm{s}$, derived from results of the OSU Tidal Prediction Model Software applied to the European Shelf (Egbert et al., 2010). Hence, the tidal current introduces primarily an alternating south-to-north current with only a small west-to-east component.

The circulation in the northern part of the North Sea is connected with the North Atlantic through the Slope Current which approximately follows the 200-m isobath along the European Continental Shelf from south to north. North of the Shetlands it enters the North Sea in the Norwegian trench and exits as the Norwegian Coastal Current (Figure 1). At slightly lesser depths (about $150 \mathrm{~m}$ ) the current turns clockwise around the Shetlands, forming the East Scotland Atlantic Inflow, which flows south along the bathymetry. At 100 meter depth, the Fair Isle Current (FIC) separates from the Slope Current (Turrell et al., 1996) and enters the northern part of the North Sea between the Orkney and Shetland Islands and follows the $100-\mathrm{m}$ isobaths, in the process passing by the 22/4b site (Figure 1). The FIC strength displays seasonal variability and has an average velocity of about $0.1 \mathrm{~m} / \mathrm{s}$ (ICES, 2005; Turrell et al., 1990) and is directed approximately to the north at the $22 / 4 \mathrm{~b}$ site following the bathymetry. See Nauw and de Haas, 2013) and Nauw et al., 2015) for a complete review of North Sea circulation with an emphasis on the hydrographic conditions around site 22/4b.

\subsection{Seasonal Thermocline}

The climatological temperature and salinity distribution in the North Sea has a strong seasonal cycle. The highest seasonal variability occurs in the shallower southern parts of the North Sea. However, in the deeper northern parts of the North Sea, a balance between the tidal and wind-driven mixing on the one hand and generation of buoyancy by solar heating on the other leads to the creation and destruction of the thermocline (Bowers and Simpson, 1987). It is at the transition between fully-mixed and stratified waters that mixing fronts occur. Climatological temperatures observations (Berx and Hughes, 2009) show that seasonal stratification starts in April/May in the central North Sea leading to mixing fronts just south of and/or around the Dogger Bank (Holt and Umlauf, 2008; Nauw et al., 2015; Pingree and Griffiths, 1978).Starting in September, it retreats to the north, passing across the 22/4b site sometime in November. Between the end of December and the end of April, the entire North Sea is wellmixed.

At the location of the tidal mixing fronts, sub-surface, along-frontal jets have been observed with speeds of 0.02 to $0.16 \mathrm{~m} / \mathrm{s}$ (Brown et al., 1999; Simpson and Pingree, 1978; van Aken et al., 1987) and cross-frontal velocities of 0.04 m/s (Hill et al., 1993; Lwiza et al., 1991; Matthews et al., 1993). The alongfrontal jet is in near geostrophic balance; deviations from geostrophy lead to a secondary circulation with upwelling at the mixed side of the front (Simpson and 
Pingree, 1978) and surface convergence (Hill et al., 1993). The typical width of the tidal mixing front is fairly narrow, only $2 \mathrm{~km}$.

Stratification directly impacts the tidal current structure, because mixing is reduced locally at the depth of the thermocline, thereby decoupling the upper and the lower layers. The horizontal tidal current vector, which forms an ellipse, can be decomposed into a clockwise and anti-clockwise circular motion. The thickness of the bottom frictional layer is different for both rotational components, which leads to a clockwise (anti-clockwise) rotation in the upper (lower) layer (Maas and van Haren, 1987; Souza and Simpson, 1996; van Haren, 2000). A more subtle effect is the clockwise veering of the direction of the maximal current speed (Lwiza et al., 1991).

A balance exists between processes that enhance the stratification, heating from the atmosphere and fresh water discharge, and the ones that cause its breakdown. The dominant processes in de-stratification are the (turbulent) heat and momentum flux by wind and (breaking) waves at the seas surface and shear-induced turbulence by bottom friction at the seabed. In general, turbulent fluxes at the thermocline are small except under certain conditions, such as breaking of internal waves which are generated by tide-topography interaction (Rippeth, 2005; van Haren et al., 1999) and shear generated by inertial currents following strong wind-forcing events (Knight et al., 2002; MacKinnon and Gregg, 2005; Rippeth, 2005; van Haren, 2000). Enhanced shear and mixing occurs when wind-stress, the bottom shear-stress (which is mostly tidally-driven), and the inertial shear-vector all are aligned (Burchard and Rippeth, 2009). The processes that cause a breakdown of the thermocline were thoroughly examined during the PRocesses of Vertical Exchange in Shelf Seas (PROVESS) experiment, which was conducted in September and October of 1998 at 59 $19.70^{\prime} \mathrm{N}$ and $01^{\circ}$ $00.22^{\prime} \mathrm{E}$ in $110 \mathrm{~m}$ water depth (Howarth et al., 2002; Figure 1). The actual breakdown of the thermocline; however, was not observed during the period in which the PROVESS experiment was executed. Model simulations indicated that the thermocline breakdown only occurred in December of that year (Bolding et al., 2002) and was related directly to the vertical heat flux driven by the turbulent mixing across the thermocline. The hydrography at the location where the PROVESS experiment was carried out is comparable to that of the 22/4b site (Figure 1), suggesting that similar processes also are occurring here. The major difference between the location of the PROVESS experiment and the 22/4b site is the presence of the large-scale bubble plume and their vertical momentum at the latter location and the FIC.

\subsection{Bubble plumes and vertical fluid motions}

Large natural bubble plumes from marine seepage (Leifer et al., 2009) and engineered bubble plumes such as used in lake destratification (Wüest et al., 1992) are associated with strong upwelling fluid motions. These motions are driven by the buoyancy flux, $Q$, which accelerates fluid vertically. The strength of the upwelling flow varies as $\mathrm{Q}^{0.3}$, with megaplumes $\left(>10^{6} \mathrm{~L} \mathrm{day}^{-1}\right)$ achieving upwelling flows of one or more meters per second (Leifer et al., 2000; Leifer et al., 2015; Wiggins et al., 2015). In the process, the upwelling flow distorts the flow streamlines associated with currents (McClimans et al., 2000). The upwelling flow carries deeper, cooler (denser) water to shallower depths, doing work against stratification (Leifer et al., 2009); however, if the ambient-plume density difference becomes too large, plume fluid detrainment occurs (Aseda and Imberger, 1993), particularly near the thermocline, where water density changes 
rapidly. The upwelling flow extends outside the bubble plume creating an upwards moving "momentum plume" surrounding the core bubble plume (Milgram, 1983). Few studies have looked at the interaction between currents, which are absent in lakes, but ubiquitous in the marine setting, and bubbleplume upwelling flows. Currents distort the momentum plume, compressing it in the upstream direction and extending it in the downstream direction (McClimans et al., 2000; Leifer et al., 2009). Detrainment of suspended material from the bubble plume can segregate detritus and upwelled fluids into the downstream momentum plume (Leifer et al., 2009) including small, dissolving bubbles (Wilson et al., 2015).

As noted, the major difference between the PROVESS and 22/4b sites is the presence of the FIC and the bubble megaplume at the latter location. Winddriven and advective transports were negligible during the PROVESS experiment (Luyten et al., 2002). Vertical transport at the 22/4b site also may be generated by bubble-induced circulation and entrainment (Woods, 2010). In this study, we hypothesize that bubble generated flows can cause the premature destruction of a seasonal thermocline, such as is common in the North Sea marine environment, and evaluate the hypothesis with data collected at the 22/4b site during a field campaign.

\section{Methods}

As part of the 22/4b study in autumn 2011, landers were deployed inside the main crater on a ledge at $118 \mathrm{~m}$ (Figure 2) slightly apart from most of the seepage vents (see figure 4 in Leifer et al., 2015). The two GEOMAR landers included 6000 m-rated logging systems to record conductivity, temperature, and pressure by a SeaCAT C-T recorder (SBE 16plus V2 with Digiquartz pressure sensor, Sea-Bird Electronics, Inc. Washington, USA), and an Acoustic Doppler Current Profiler (ADCP, 300 kHz Workhorse Sentinel, Teledyne RD Instruments, Poway, USA) that recorded vertical profiles of ocean currents and acoustic intensities. Lander-1 was deployed during the GEOMAR research cruise AL374 with the $R / V$ Alkor on 7 June 2011. Lander-1 was recovered by ROV and swapped with Lander-2 during a survey campaign with the Dutch survey vessel SV Noordhoek Pathfinder on 9 September 2011. Lander-2 also was deployed on the same terrace, in an adjacent location and recovered on 19 April 2012 on the Max Planck Institute research cruise HE377 by RV Heincke.

The sample interval of the $\mathrm{C}-\mathrm{T}$ recorders on both landers was set to 5 minutes; for the C-T on Lander-1 an ensemble averages of 20 measurements were recorded, whereas the ensemble averages of the C-T sensor on Lander- 2 were based on only 5 measurements. An integration time of 5 seconds was taken for the 10,000 psi Digiquartz pressure sensors to achieve a depth resolution of better than $0.01 \mathrm{~m}$. The sensor specifications of the new recorders

(http://www.seabird.com/sbe16plusv2-seacat-CTD) are provided in Table 1. The salinity data showed significant drift and therefore was not used in the analysis. Many of the ADCP settings of the Landers were the same for both deployments. The salinity was set to $S_{0}=35$ PSU and the bin size was $1 \mathrm{~m}$. Some of the settings were slightly different (Table 2); especially the different time per ensemble leads to different temporal resolutions of 144 and 96 cycles per day, respectively. 
For processing, ADCP data above the sea surface (echoes) were removed. In terms of acoustic backscatter, the surface is defined by the location where the acoustic backscatter suddenly increases significantly. So, we define the sea surface as the bin with the highest increase in acoustic backscatter compared with the next deeper bin in the water column. This bin location is different for each of the four beams as the lander was not level; pitch and roll influence the bin location. Vertical bins then were mapped using pitch, roll, and heading following the coordinate transformation method as described in the ADCP manual (Teledyne RD Instruments, 2010) leading to the horizontal and vertical position $(x, y, z)_{1,2,3,4}$ of the bins for each beam $(1,2,3,4)$ w.r.t. the device. Data in the bins above the mean distance between the device and the surface in the beam direction were set to not a numbers $(\mathrm{NaN})$ in the backscatter intensity data. Bins above the minimum distance between the device and the surface in the beam direction may be subjected to side-lobe interference and also were set to $\mathrm{NaN}$ in the velocity data. The heights above the lander are corrected such that sea level elevation is continuous between landers including the addition of $1 \mathrm{~m}$ to the lowest depth bin to correct for the ADCP position w.r.t. the seafloor. The calculation of Cartesian velocities from the radial velocities in the beam directions assumes horizontal homogeneity, which is incorrect when bubble(s) rise through the beams because they are not passive fluid tracers, but have distinct, sizedependent rise rates compared to the motion of passive tracers of fluid motions within the water column.

The level of horizontal velocity inhomogeneity is indicated by a high absolute value for the error velocity, $v_{\text {err }}$. High backscatter intensity (bubbles or bubble plumes crossing the beams) was correlated with high $\left|v_{e r r}\right|$ and (an unrealistically) high eastward velocity component. This likely is caused by a failure of the horizontal homogeneity assumption. In velocity estimates, data with $\left|v_{e r r}\right|>0.1 \mathrm{~m} / \mathrm{s}$ were set to $\mathrm{NaN}$ and not used in the analysis; the same holds for the data with $v_{e r r}=0$, which result from the so-called 3-beam solutions. Nevertheless, for both cases, data is retained in the echo intensity to better distinguish bubble plume-driven flow, easily identified by the high acoustic backscatter intensity, from undisturbed flow. The absolute value of the vertical shear, $|S|=\sqrt{\left(\frac{d u}{d z}\right)^{2}+\left(\frac{d v}{d z}\right)^{2}}$, is derived from the vertical gradients of horizontal velocities, $u$ and $v$, over $4-m$ bins.

A least squares harmonic analysis (LSHA) was applied to the depth-averaged values $(\bar{u}, \bar{v}, \bar{w})$ using the freely available MATLAB program T_Tide (Pawlowicz et al., 2002). In a LSHA, time-series are modeled as a sum of a finite set of sinusoids at specific frequencies related to the astronomical tides, leading to amplitudes (indicated with a capital letter) and phases (indicated with $\varphi$ ) as well as the long-term average value (subscripted 0 ), called residual. Unless stated otherwise, we use the 35 most dominant tidal constituents.

Beside climatological Sea Surface Temperature (SST), $T_{C S}$ and near bottom temperature, $T_{C B}$ (Berx and Hughes, 2009), also the 8-day composite SST data from MODIS, $T_{M S}$ (MODerate resolution Imaging Spectrometer) $L 3$ data product (http://oceandata.sci.gsfc.nasa.gov/ have an imaging footprint of $\sim 1 \mathrm{~km}$ and were used in the analysis (Hosoda et al., 2007). 


\section{Results and Discussion}

\subsection{Temperature measurements}

\subsubsection{Time-series analysis}

The long-term near-seabed temperature time-series, $T_{L B}$ (Figure 3 ) obtained from the two lander deployments shows temperatures ranged between 6.6 and $10.7^{\circ} \mathrm{C}$. Maximum near-seabed temperatures of $T_{L B}=10.7^{\circ} \mathrm{C}$ are observed in the end of November. Near-seabed temperatures decreased towards a minimum of $T_{L B} \sim 7^{\circ} \mathrm{C}$ by mid-February, thereafter stabilizing at $T_{L B} \sim 7.2^{\circ} \mathrm{C}$. From the peak in the end of November until the February minimum, near-seabed temperatures decreased approximately linearly.

Variations between the climatological near bottom temperature, $T_{C B}$, and the maximum temperature at the lander, $T_{L B}$, appear to increase throughout autumn. At approximately the same time that $T_{M S}$ crosses the near seabed temperatures, the abrupt temperature swings observed by the lander in bottom temperature, $T_{L B}$, ceased. The seabed temperatures, $T_{L B}$, are a bit higher than $T_{M S}$, suggesting an unstable water column. Some of the difference could be due to the large imaging footprint of MODIS in the presence of large-scale spatial temperature trends, the fact that the data are 8-day composites and the potential for a skin temperature bias (see below). However, there was good agreement between the temperature values of the landers, $T_{L B}$, and the observed CTD profile temperatures, $T_{C T D B}$, and between $T_{M S}$, and CTD profile SST temperatures, $T_{C T D S}$ (Figure 3) obtained during the SV Noordhoek Pathfinder and RV Heincke cruises. High-frequency $T_{L B}$ variations between the end of November 2011 and the end of April 2012 are small, less than $0.1^{\circ} \mathrm{C}$. This is in sharp contrast with the large amplitude variation, $\Delta T_{L B}$, observed starting mid-summer and throughout autumn of 2011 , with amplitudes as large as $\Delta T_{L B}=2^{\circ} \mathrm{C}$. These likely were not wave or storm driven as they are uncorrelated with high RMS wave heights or wind stress (Figure 3). In 2011, the stormy season started with several shortlived, weak storms in October, while November was relatively quiescent. Finally, in December the weather became dominated by very strong storms. These large, autumn seabed variations in $T_{L B}$ either were generated by horizontal advection or by bubble-induced overturning or entrainment of warmer water from the upper mixed-layer. However, creation of the observed temperature pattern would require a front of sharply different seabed water masses to repeatedly cross the 22/4b site - a North Sea equivalent of the Gulf Stream - yet oceanographic data for the deeper water-column (Berx and Hughes, 2009; Otto et al., 1990) do not indicate such a persistent oceanographic feature in the central North Sea. This makes horizontal advection a very unlikely mechanism contrary to bubbleinduced overturning or entrainment.

$T_{M S}$ first decreased below $T_{L B}$ on 9 November 2011.This suggests that the water column became vertically well-mixed afterwards until summer stratification began in 2012 after final recovery of the lander. From 9 November onwards, $T_{M S}$ seems to be slightly lower than the lander temperatures measured near the seabed, $T_{L B}$. This may have to do with the fact that the satellite only observes the temperature of the top most layer (skin temperature), which introduces a negative bias of 0.1 to $0.2 \mathrm{~K}$ compared to water-column temperatures (Donlon et al., 2002). Climatological data (Berx and Hughes, 2009) indicate a 
temperature difference of $T_{C S}-T_{C B}=0.7 \mathrm{~K}$ between the surface and the bottom in November and $\mathrm{T}_{\mathrm{CS}}-\mathrm{T}_{\mathrm{CB}}=0.3 \mathrm{~K}$ in December at the location of the 22/4b site, indicating that the climatological breakdown of the thermocline likely occurred between mid-November and mid-December in this area.

As noted, the large $T_{L B}$ variations observed during the end of summer and throughout autumn 2011 abruptly ceased on 9 November once $T_{M S}<T_{L B}$ (Figure $3)$. The local minima in $T_{L B}$ observed in the period from June to October corresponds well with the climatological values, $T_{C B}$ (Berx and Hughes, 2009), whereas local maxima during this period most likely are related to downward transport of warmer surface water. Most of these peaks occur during relatively fair weather conditions as shown by the relatively low RMS wave height (Figure 3, lower panel). Two possible explanations include internal wave breaking and bubble-plume driven fluid motions, specifically, the recirculation downwelling flow, both of which could drive downward mixing of upper-layer water, yet are unrelated to surface processes. Therefore, the abrupt cessation of large near-bed temperature variations suggest establishment of a vertically well-mixed water column on 9 November. In the next section we analyze the ADCP data to test the hypothesis that these strong seabed temperature fluctuations are related to bubble-plume upwelling and downwelling flows mixing warm upper-layer water.

\subsubsection{Stratification of the water column}

After deployment of Lander-2, a set of CTD casts was performed above the crater and on each of the corners of the survey site (Leifer and Judd, 2015). Figure 4 shows that the bottom of the mixed layer depth (MLD) is at $\sim 13^{\circ} \mathrm{C}$ and the top of the base of the thermocline (BTH) is at $\sim 10^{\circ} \mathrm{C}$, where MLD and BTH are defined as the location where the vertical temperature gradient, $\mathrm{dT} / \mathrm{dz}$, exceeds $0.1^{\circ} \mathrm{C} / \mathrm{m}$. There seem to be indications that the location of the MLD and the BTH vary with the tide. A LSHA was applied to the MLD and BTH with only the M2 tidal constituent. The average height of the MLD (BTH) was $45 \mathrm{~m}(56 \mathrm{~m})$ and the amplitude on the M2 tidal frequency was $5.5 \mathrm{~m}(6.2 \mathrm{~m})$. The height of the MLD (BTH) exhibited a phase lag with respect to the tidal sea level elevation of $198^{\circ}\left(233^{\circ}\right)$. In the next section a physical process will be proposed that can explain such variability in the height of the thermocline. 


\subsection{ADCP observations}

\subsubsection{Total water depth, pitch, roll and heading}

The pitch, roll and heading show a large change on 9 September (2011) when Lander-1 was replaced with Lander-2 (Figure 5b,c). In addition, an anomalous event occurred on 8 December around 20:15. Before this event, the mean lander water depth was $111.7 \mathrm{~m}$ and after that the mean lander water depth increased to $118.3 \mathrm{~m}$ (Figure 5a). This increase in water depth occurred simultaneously with strong changes in pitch, from $6.4^{\circ}$ to $0.8^{\circ}$, and heading, from $136.3^{\circ}$ to $143.2^{\circ}$. Smaller changes in pitch, roll, and heading also were observed earlier. This suggests that the lander either was located on an unstable plateau and/or shifted under conditions associated with the anomalous event. The maximum pitch and roll were $11.6 \%$ and $13.6 \%$, respectively, which is still within the allowable tilt range of $\pm 15 \%$ for an ADCP.

The event on 8 December was recorded by a hydrophone system mounted on the lander and exhibited strongly elevated acoustic energy extending in frequency to $100 \mathrm{kHz}$ and higher in a short pulse (Wiggins et al., 2015). They interpreted this acoustic event as an eruption lasting for approximately 12 seconds. After the event, the broad-band sounds returned to quasi steady-state in spectra and amplitude but at far higher levels than before the event, suggesting a dislocation of the lander closer to the bubble seeps and from the presence of higher frequency component, an increase in emissions. Also consistent with this record were seabed morphology changes in the crater observed during a ROV-dive in autumn 2012 (Linke, 2012), which documented a new jagged rift (Wiggins et al., 2015; Figure 3), with a stronger bubble plume than any observed during the autumn 2011 campaign from the crater wall.

\subsubsection{Velocity}

Lander-1 (Lander-2) had a fairly significant roll (pitch before 8 December 2011). This means that beam 2 (beam 3 ) was nearly facing upward on Lander-1 (Lander-2) and that beam 1 (beam 4) was at an angle between 30 and $35^{\circ}$. Side-lobe interference leads to unreliable velocity data in the upper $16 \%$ of the water column for Lander-1; these percentages were $14 \%$ and $7 \%$ for Lander-2 before and after the 8 December 2011 event, respectively (white in Figure 7). During periods of negative eastward velocities (ebb), the acoustic backscatter is much smaller and shows a local maximum between 70 and $80 \mathrm{~m}$ above the seabed (boxes in the middle panel of Figure 6). Particularly in the last four hours without bubble influence this appears to correlate with a small velocity jump between the upper layer with approximately zero velocity and the lower layer with a velocity of $\sim 0.2 \mathrm{~m} / \mathrm{s}$, especially between 19:00 and 23:00 UTC on 16 September 2011 (indicated by the box in Figure 6). The current structure is influenced by turbulence damping at the thermocline, which affects the counterrotating tidal ellipses in a different fashion, creating local shear at the thermocline (Maas and van Haren, 1987). Local maxima in the backscatter intensity and shear are indications of the thermocline location and are used in section 3.6 to establish a thermocline detection algorithm. 
The daily mean eastward and northward velocity components for Lander-1 and Lander-2 (Figure 7) seems to be slightly discontinuous between the period of Lander-1 and Lander-2, which suggests that Lander-1 may have been located closer and/or angled towards an area of active bubble plume emissions. Horizontal current velocities above the bottom boundary layer appear to be continuous before and after the event of 8 December 20:15 UTC, 2011, however, vertical velocities show a marked jump to values approaching $0.5 \mathrm{~m} / \mathrm{s}$. The residual depth-averaged velocity is $\left(u_{0}, v_{0}, w_{0}\right)=(0.23,0.22,0.20 \mathrm{~m} / \mathrm{s})$ for the entire measurement period from 7 June 2011 to 19 April 2012. The analysis only explains 16,8 , and $7 \%$, respectively, of the total variance of the timeseries of $(\bar{u}, \bar{v}, \bar{w})$ when retaining only the significant tidal constituents (usually less than 10 out of the 35 astronomical frequencies). The M2 tidal amplitude is the strongest contributor by far to the horizontal velocities and has an amplitude of $\left(U_{M 2}, V_{M 2}, W_{M 2}\right)=(0.10,0.05,0.01 \mathrm{~m} / \mathrm{s})$. The reconstructed velocity in the northward (eastward) direction, retaining only the variability on the significant tidal frequencies, varies between +0.18 and $+0.28 \mathrm{~m} / \mathrm{s}(+0.10$ to $0.32 \mathrm{~m} / \mathrm{s})$, which is slightly less than the observations at the forties site located at $\left(57^{\circ} 43^{\prime} \mathrm{N}\right.$, $1^{\circ} 01^{\prime} \mathrm{E}$ ), or $40 \mathrm{~km}$ to the southwest of the $22 / 4 \mathrm{~b}$ site (Graham, 1985).

The time-series of the depth-averaged velocities in each of the earth coordinates (Figure 8) clearly shows small changes related to the transition from Lander-1 to Lander-2 on 9 September and larger changes associated with the 8 December event. Also, a LSHA was applied to the individual periods and the results are shown in Table 3. The most obvious changes occur in the residual (or tidallyaveraged) upward velocity, which increased from $\sim 0.10$ to $\sim 0.33 \mathrm{~m} / \mathrm{s}$. This change cannot be ascribed to an erroneous projection of the velocity data in earth coordinates, in which horizontal currents are projected on the vertical component, because the horizontal speed, defined:

$V_{h}=\sqrt{u^{2}+v^{2}}$

does not show a significant change on 8 December, unlike the absolute speed which is defined: $V_{a}=\sqrt{u^{2}+v^{2}+w^{2}}$

One possible explanation is that the increase in the vertical velocity relates to the different distance between the ADCP beams and the nearest bubble plume or seep, a likely explanation of some of the changes in the passive acoustic measurements (Wiggins et al., 2015). Apparently, in the third period the lander was nearer to the bubble plume than in the first two periods, leading to a longterm mean upward velocity of $+0.33 \mathrm{~m} / \mathrm{s}$, which is comparable to the reported unintentional and uncontrollable rise of the (neutrally-buoyant) submersible, JAGO of $\sim 0.17 \mathrm{~m} / \mathrm{s}$ during one of its dives through the bubble plume (Schneider von Deimling et al., 2015). JAGO's upwards velocity must have been caused by the bubble plume upwelling flow momentum.

\subsubsection{Thermocline detection algorithm}

Turbulent transport induces upward advection of nutrients and suspended particulate matter (SPM) from the sea floor, but is reduced significantly at the thermocline. The latter effectively blocks nutrient and SPM transport. Light penetration in the water column is reduced by SPM, which is constrained below the thermocline, introducing a local optimum for algae and other species just below the thermocline, indicated by higher acoustic backscatter (but also if present, high turbidity, lower transmissivity, and an oxygen minimum layer). This material causes a small local peak in the reflected backscatter intensity that 
a thermocline detection algorithm (TDA) was developed to identify. The backscatter intensity profiles are stored for each of the beams separately. The backscatter intensity was a bimodal distribution with the stronger local maxima related to the highest acoustic backscatter from bubbles or bubble plumes bubbles are acoustically much more reflective than the reflective material at the thermocline (the weaker local maxima). A clear threshold value could be identified from the bimodal distribution of the backscatter intensity at the local maxima, below which local maxima in the backscatter intensity are related to the thermocline. The height above the seabed of the local maxima was determined for each of the four beams, leading to four estimates of the height of the local peak for every ensemble (velocity profile). A key assumption is that the thermocline depth can be assumed to be much more horizontally homogeneous than the vertical location of the bubbles or bubble plumes. Obviously, bubbles rise to the surface while being advected horizontally through the beams of the ADCP. As an example, beams at either side of the ADCP have their acoustic footprint more than $130 \mathrm{~m}$ apart at $70 \mathrm{~m}$ above the device, due to the angle of the beams of $20^{\circ}$ from the vertical. Hence, for a bubble rise speed of $0.33 \mathrm{~m} / \mathrm{s}$ Table 3 and a horizontal speed of $1 \mathrm{~m} / \mathrm{s}$, the bubbles will have risen about $40 \mathrm{~m}$ over the distance between the beams. In contrast, horizontal variations in the thermocline depth over the beam spread distances should generally be much less than $5 \mathrm{~m}$. The TDA exploits this difference in horizontal homogeneity. Within each period of an hour, the median is taken of the height of the local maxima having an acoustic backscatter less than the threshold value for each of the four beams. If at least 5 different heights within this hour were within $2 \mathrm{~m}$ of that median value, the latter value was taken to be an estimate of the thermocline height, $H_{T}$, and applied to the central time. See the Appendix for a detailed and graphical explanation of the steps in the TDA.

The acoustic backscatter data of beams 1 and 2 in Figure 9 represent the best and worst case scenario for detecting the local backscatter intensity maximum, respectively; data of beams 3 and 4 (not shown) are intermediate cases that were included in the analysis. Beams 1 and 2 are on opposite sides of the ADCP with apparently beam 2 apparently closest to the bubble plume. The bubble plumes induce a periodically strong acoustic backscatter signal that completely obscures the local peak in acoustic backscatter, which likely was induced by the thermocline height. Unfortunately, most CTD-profiles were collected during the period when the backscatter intensity structure was determined completely by the bubble plumes passing through the beams. However, there is a reasonable correspondence between the estimates of the average MLD from the TDA and from the CTD profiles. A mid-depth local maximum in the absolute shear, $|S|$, is observed around the mean location of the MLD using the TDA or derived from the temperature profiles (Figure 9c). The local maximum in the shear at the location of the pycnocline is between 0.03 and $0.04 \mathrm{~s}^{-1}$ and is comparable to the vertical shear observed during the PROVESS experiment as shown by Knight et al., 2002). In the latter paper, these shears were found to be associated with inertial oscillations.

The variation in MLD seems to relate to the presence or absence of a bubble plume influence. Especially, on 10 September, a more-or-less continuous rise of $\sim 11 \mathrm{~m}$ in the MLD and BTH derived from CTD profiles is correlated to the presence of high acoustic backscatter values throughout the water column. During the following day, a similar rise of the local maximum in the backscatter intensity from 72 to $78 \mathrm{~m}$ height above the lander was observed in relation to high acoustic intensities. It is probable that upward flows generated by the 
bubble plume lift the thermocline locally by several meters, a process that ceases to be observed in ADCP data when the bubble plume is advected away from the beams.

\subsection{Timing of the thermocline breakdown}

Even though thermocline height appears to vary with the tide, daily mean values and their standard deviation were determined whenever at least 10 estimates were available for a day. The results in Figure 10 show that the thermocline already is present at the start of the time-series in June 2011, which was confirmed by the CTD-profiles taken before deployment of Lander-1 (see temperature difference between surface and bottom in Figure 3). Moreover, the thermocline then deepens until reaching a final depth of $\sim 40 \mathrm{~m}$ below the sea surface, where it remains throughout the summer. In early October 2011, the mixed layer deepens further until it is no longer visible in the backscatter intensity, starting around 16 October 2011. This is about two weeks earlier than when $T_{M S}$ and $T_{L B}$ converge (Figure 3 ). This could be the result of a failure of the TDA towards the end of October. For example, the local maximum may deepen to levels where it is obscured by the high acoustic intensities near the device, or the maximum may exceed 90 counts, the threshold detection value. Visual inspection showed a possible thermocline located at 30 to 40 meters above the seafloor on 16 October, which was not captured by the TDA; however, it no longer was separated clearly from the high acoustic backscatter signal from the bubble plume and therefore is not shown in Figure 10.

Zooming in on the period October to early December shows a strong, almost linear decrease of $B T H$ indicated by the drawn line in Figure 11 . The dashed lines give the $95 \%$ prediction intervals, providing an estimate of the interval in which future observations will fall. Note that these are much wider than the $95 \%$ confidence intervals and therefore more suitable for extrapolation. Details on the derivation of the prediction interval can be found in Appendix $B$.

The depth of the mid-depth maximum absolute value of the shear, $\left|S_{\max }\right|$, follows the same linear trend (bottom panel of Figure 11). The 4-bin averaged shear itself contained significant noise; therefore, a 2 hour running average was applied to calculate the shear with a further criterion requiring at least 5 profiles to be available within the window. The extrapolated approximate height of the thermocline, BTH, crosses the bottom boundary layer $(\sim 15 \mathrm{~m}$ above the seafloor) at about 31 October; 95\% confidence intervals show it to occur between 26 October and 5 November. Within this interval, the maximum shear in the bottom boundary layer (band with reddish colors between 5 and $15 \mathrm{~m}$ above the sea-floor) suddenly disappears, indicated by the black box; here, the bottom boundary layer appears to separate from the seafloor. This probably is related to the interaction of the thermocline with the bottom boundary layer, causing the lower layer to become quiescent (zero-flow) and the maximum shear layer to be lifted above the thermocline. This suggests that the complete breakdown of the thermocline occurred between 31 October and 11 November. Besides that, note the intensified shear (reddish colors) near the surface from 25 November onwards. This must be related to wind- and wave-driven shear in the near surface layer (see Figure 3, bottom panel). However, by that time the thermocline already had broken down, so intensified surface mixing cannot be the primary reason for the thermocline breakdown. 
The timing of the breakdown also may be derived from the temporal behavior of the horizontal velocities, because they could signify the passage of a frontal jet (Brown et al., 1999; Hill et al., 1993; Simpson and Pingree, 1978; van Aken et al., 1987). To remove variations related to the tides, a running window LSHA was applied separately to the time-series of the horizontal velocities, $u$ and $v$ at each depth. A window of 1 day was chosen and the LSHA analysis was applied using only the (dominant) M2-tidal component having a frequency of 12.25 hours. This leads to an amplitude and phase at the M2 tidal frequency and a residual (or mean) value for both the eastward and northward component of the velocity at each depth. Using the tidal amplitudes and phases of the eastward and northward components, the ellipse parameters of the M2 tidal flow also were determined. The most obvious structure in Figure 12 is the reversal of the residual northward current between 25 October (noon) and 29 October throughout the entire water column. Within this period the maximum (absolute) residual velocity $\left(u_{0}, v_{0}\right)=(0.7,-0.25) \mathrm{m} / \mathrm{s}$ is observed at $\sim 75 \mathrm{~m}$ above the seafloor, whereas the time-mean residual velocity at this depth is $\left(u_{0}, v_{0}\right)=$ $(0.3,+0.15) \mathrm{m} / \mathrm{s}$. This phenomenon likely is related to a frontal jet-like structure - similar ones have been observed in the southern part of the North Sea, albeit with a much smaller maximum along (cross) frontal velocities of only $0.15(0.05)$ $\mathrm{m} / \mathrm{s}$ (Hill et al., 1993). In our study, additional (continuously weaker) jets appear around 5, 13, 26, and 31 November. This suggests that in the period between late October and the end of November, when the jets appear at a regular basis, the bottom seasonal front moves repeatedly back and forth across the 22/4b site. The frontal jets themselves are not the cause for destratification, they are a result of the passage of the tidal mixing front.

\section{Summary and Conclusions}

In this paper we have provided 5 different pieces of evidence to show that the breakdown of the thermocline at site 22/4b most likely occurs on 9 November 2011, e.g.

1) The Modis Sea Surface Temperature, $T_{M S}$ was lower than the near seabed temperatures at the lander location after 9 November. Even though satellite temperature observations may be subjected to skin temperature bias, this suggests a well-mixed or nearly well-mixed water column.

2) The large amplitude temperature variations, likely caused by bubbleinduced overturning or entrainment, abruptly ceased on 9 November 2011. Advection likely was not the cause for these variations, as horizontal nearbottom temperature variations are too small in that area of the North Sea.

3) The height of the thermocline derived from Acoustic Doppler Current Profiler intensity measurements was estimated using the thermocline detection algorithm. Linear extrapolation of the location of the height of the thermocline shows that the breakdown of the thermocline occurred between 31 October and 11 November (based on the $95 \%$ prediction intervals) and most likely on 5 November.

4) The local maximum in the vertical shear was located at $\sim 20 \mathrm{~m}$ above the bottom between 25 and 30 October and fell within the $95 \%$ prediction interval. The location of the local maximum in the shear was identified as correlated with the height of the thermocline. Soon after 30 October, the maximum shear layer 
becomes invisible in the high shear layer resulting from the near-bottom boundary layer.

5) The breakdown of the thermocline or the passage of the seasonal front at the 22/4b site is accompanied by a strong frontal jet of $\sim 0.3 \mathrm{~m} / \mathrm{s}$ between 26 and 29 October. It is about twice as large as previous observations of the seasonal frontal jet in the North Sea (Brown et al., 1999; Hill et al., 1993; Pingree and Griffiths, 1978; Simpson and Pingree, 1978; van Aken et al., 1987). Moreover, the passage of the frontal jet is not restricted to one single episode, but the frontal jet appears to move across the 22/4b site at certain intervals, although it had weakened with every passage. The breakdown of the thermocline likely occurs in phases; between the stratified period and the well-mixed period there must be an intermediate phase in which the water column experiences periodic stratification; in this phase a subtle balance exists between processes that cause stratification and mixing processes. The strength of these processes varies over time, such as for instance with variations in the heat flux, but also with the tidal mixing strength (spring-neap) and space, e.g. mainly from advective processes.

The thermocline breakdown at the 22/4b Site in 2011 was well before the observed breakdown in 1998 at a similar location only $160 \mathrm{~km}$ to the Northeast during the PROVESS study (Howarth et al., 2002). At the latter location, the thermocline remained intact at least until 9 November, when a $2.1 \mathrm{~K}$ temperature difference between the surface $\left(9.5^{\circ} \mathrm{C}\right)$ and the near bottom waters $\left(7.4^{\circ} \mathrm{C}\right)$ still was observed. In addition, model simulations for the PROVESS study indicated a breakdown of the thermocline early December (Bolding et al., 2002). The thermocline breakdown at the 22/4b site in 2011 also was earlier than expected from climatology in this area (Berx and Hughes, 2009), which indicates a breakdown in the end of November/early December. In Figure 10 of Nauw et al., 2015), it can be seen that the difference in climatological temperature between the sea surface and near-bed layer is very similar at both sites throughout the year.

It appears that the breakdown of the thermocline near the 22/4b site in 2011 occurs anomalously early in the season with respect to nearby locations. Fluid in the bubble momentum plume appears to rise at an average $0.33 \mathrm{~m} / \mathrm{s}$, whereas the bubbles themselves rise at $0.25-0.30 \mathrm{~m} / \mathrm{s}$ faster than the surrounding flow. The bubble-plume induced flow likely causes additional turbulent mixing and can generate entrainment of the surface mixed layer (Wüest et al., 1992). Therefore the data are consistent with the hypothesis that strong bubble plumes provide a mechanism that assists in breaking down of the seasonal thermocline.

The thermocline detection algorithm validity was confirmed in data collected every 2 seconds with a coupled ADCP, e.g. having 8 beams to minimize bubble contamination, on a lander placed in close proximity of a natural bubble seep near Dogger Bank (Brussaard et al., 2013). Moreover, first inspection of the data collected at Dogger Bank indicated high frequency wavelike structures in the thermocline with periods of about 10 minutes.

Although the data analysis is consistent with the hypothesis of bubble plume mixing affecting local thermocline breakdown, further detailed analysis of these data and or collection of new datasets are needed to shed further insights into bubble-plume-induced destratification and/or mixing processes at sea. 


\section{Appendix A - Thermocline Detection Algorithm}

The thermocline detection algorithm (TDA) consists of several different steps. First of all, a peak detection algorithm is applied to the logarithm of the backscatter intensity data, $\log (I)$. A local peak in the vertical profiles of the $\log (I)$ is defined as when the maximum value is at least 1.1 Counts higher than its neighboring values just above and below (black dots in Figure A-1, left panel). Three local maxima can be identified in the example of Figure A-1; the on at the seafloor is related to the reflected sound being highest closest to the ADCP. The second peak at about $30 \mathrm{~m}$ above likely is related to a bubble plume and the top most relative maximum near $70 \mathrm{~m}$ height is likely related to the MLD. The right panel of Figure A- 1 shows that the local maxima are bimodally distributed.

Bubbles are acoustically very reflective, whereas the thermocline has much less reflective capabilities. Therefore it is safe to assume that the higher acoustic maxima are related to bubbles and the lowest to the MLD. Thus, the maximum threshold for local maxima associated with the MLD is set to $\log (I)<4.5$ (dashed line).

The location of all local maxima between 9 September 2011, 17:15 UTC and 11 September 2011, 5:15 UTC are shown in Figure A- 2 for beam 1 only, where local maxima with $\log (I)<4.5$ are marked black and the local maxima that fail this criterion are marked white. Obviously, most of the white dots are either related to being near-seabed values or they are related to high acoustic reflections from rising bubble plumes. However, there still appear to be some outliers in the derived MLD that are not removed with this criterion only. Therefore, we apply the above described method to all four of the beams individually (Figure A-3). Areas where the dot-density is high are clearly related locations where a local maximum is found below the threshold value in more than one beam or at subsequent times; individual dots are observed at a depth completely unrelated to the estimates of the MLD at nearby measurements in time or space (e.g. other beams).

A median depth and running window filter is applied with a window length of one hour and a range of $\pm 2 \mathrm{~m}$ around the median value within that window.

Graphically, this filter is shown in Figure A- 4, where a box is placed with \pm 0.5 hour around the central time and $\pm 2 \mathrm{~m}$ around the median value determined for all values within that hourly window. Whenever at least 5 estimates of the MLD are present within this box, the mean thermocline height, $H_{T}$, was applied to the central time. For midnight between 9 and 10 September, only four estimates are available, leading to $H_{T}=$ NaN. For midnight between 10 and 11 September, 10 estimates are available and the mean thermocline height becomes $H_{T}=75.6 \mathrm{~m}$ (red dot).

\section{Appendix B - Confidence and Prediction Intervals}

A plausible range around a linear regression can be expressed by the confidence and prediction intervals. To determine the confidence and prediction intervals the following holds:

$y=\hat{y} \pm t_{\text {crit }}$ s.e.

With $t_{\text {crit }}$ the critical t statistic and where the standard error, s.e., is defined as: 
s.e. $=s_{y x} \sqrt{p+\frac{1}{n}+\frac{\left(x_{i}-\bar{x}\right)^{2}}{S S_{x}}}$

With $s_{y x}$ the standard error of the estimate; $p=0$ for confidence intervals and $p=1$ for prediction intervals, $\mathrm{n}$ the number of degrees of freedom; $\bar{x}$ the average of the $x$ values and

$S S_{x}=\sum_{i}^{n-2}\left(x_{i}-\bar{x}\right)^{2}$

$\mathrm{SS}_{\mathrm{x}}$ is the standard deviation. The values of these parameters and the result of the linear regression are given in Table B-1.

The $95 \%$ confidence interval leads to a space around the linear regression and indicates that the probability that the true best-fit for the data is any straight line that can be drawn in that space. However, if one takes any specific value of $x$ and wants to determine the range around the predicted value y with a $95 \%$ probability, the $95 \%$ prediction interval is to be determined. The prediction interval is wider than the confidence interval and therefore more suitable for predictions outside the sampling data, e.g. in the case of linear extrapolation.

\section{Acknowledgements}

Our thanks go to the captain and crews of S/V Noordhoek Pathfinder, R/Vs Alkor, and Heincke for their excellent and professional work throughout the cruises where the Landers were deployed, exchanged and recovered. We like to thank Dr. Frank Wenzhöfer (MPI-Bremen, Germany) for the final recovery of the lander and providing us with the CTD-profile data of the April 2012 cruise HE377 by RV Heincke. The technology and logistics center (TLZ) at GEOMAR is acknowledged for excellent logistic support. Furthermore, we thank Prof. Dr. Leo Maas (Royal NIOZ) for the valuable discussions on contents of the paper and three anonymous reviewers for their comments and suggestions on the manuscript.

\section{References}

Aseda, T., Imberger, J., 1993. Structure of bubble plumes in linearly stratified environments. Journal of Fluid Mechanics 249, 35-57.

Berx, B., Hughes, S. L., 2009. Climatology of surface and near-bed temperature and salinity on the north-west European continental shelf for 1971-2000.

Continental Shelf Research 29 (19), 2286 - 2292.

Bolding, K., Burchard, H., Pohlmann, T., Stips, A., 2002. Turbulent mixing in the Northern North Sea: a numerical model study. Continental Shelf Research 22 (18-19), 2707 - 2724, physics of Estuaries and Coastal Seas, Volume II: Proceedings of the tenth biennial conference, Norfolk, Virginia, USA, 7-11 October 2000.

Bowers, D., Simpson, J., 1987. Mean position of tidal fronts in European-shelf seas. Continental Shelf Research 7 (1), 35 - 44.

Bradley, E., 2013. Characterizing methane emissions at local scales with a 20 year total hydrocarbon time series, imaging spectrometry, and web facilitated analysis. Department of Geography. University of California, Santa Barbara. 
Brown, J., Hill, A., Fernand, L., Horsburgh, K., 1999. Observations of a seasonal jet-like circulation at the central North Sea cold pool margin. Estuarine, Coastal and Shelf Science 48 (3), $343-355$.

Brussaard, C., Greinert, J., Nauw, J., de Vries, J., Urban, P., Pohlman, J., Kool, D., Bombach, P., 2013. Cruise report RV Pelagia cruise 64PE376, NIOZ Monitoring leg1 -'Methane Bubbles'-. Tech. rep., Royal Netherlands Institute for Sea Research.

Burchard, H., Rippeth, T. P., 2009. Generation of bulk shear spikes in shallow stratified tidal seas. J. Phys. Oceanogr. 39 (4), 969-985.

Clark, J. F., Washburn, L., Hornafius, J. S., Luyendyk, B. P., 2000. Dissolved hydrocarbon flux from natural marine seeps to the southern california bight.

Journal of Geophysical Research: Oceans (1978-2012) 105 (C5), 11509-11522. Donlon, C. J., Minnett, P. J., Gentemann, C., Nightingale, T. J., Barton, I. J., Ward, B., Murray, M. J., 2002. Toward improved validation of satellite sea surface skin temperature measurements for climate research. J. Climate 15 (4), 353-369.

Egbert, G. D., Erofeeva, S. Y., Ray, R. D., 2010. Assimilation of altimetry data for nonlinear shallow-water tides: Quarter-diurnal tides of the Northwest European Shelf. Continental Shelf Research 30 (6), $668-679$.

Etiope, G., Lassey, K., Klusman, R., Boschi, E., 2008. Reappraisal of the fossil methane budget and related emission from geologic sources. Geophys. Res. Lett. 35, L09307.

Graham, C., 1985 . Forties sheet $57^{\circ} \mathrm{n}-00^{\circ}$ including part of cod $57^{\circ} \mathrm{n}-02^{\circ} \mathrm{e}$. Tech. rep., British Geological Survey 1:250,000 Series, SeaBed Sediments. Hill, A. E., James, I. D., Linden, P. F., Matthews, J. P., Prandle, D., Simpson, J. H., Gmitrowicz, E. M., Smeed, D. A., Lwiza, K. M. M., Durazo, R., Fox, A. D., Bowers, D. G., Weydert, M., 1993. Dynamics of Tidal Mixing Fronts in the North Sea [and Discussion]. Philosophical Transactions of the Royal Society of London. Series A: Physical and Engineering Sciences 343 (1669), 431-446.

Holt, J., Umlauf, L., 2008. Modelling the tidal mixing fronts and seasonal stratification of the Northwest European Continental shelf. Continental Shelf Research 28 (7), $887-903$.

Hornafius, S., Quigley, D., Luyendyk, B., 1999. The world's most spectacular marine hydrocarbons seeps (Coal Oil Point, Santa Barbara Channel, California): Quantification of emissions. Journal Geophysical Research - Oceans 104, 2070320711.

Hosoda, K., Murakami, H., Sakaida, F., Kawamura, H., 2007. Algorithm and validation of sea surface temperature observation using MODIS sensors aboard terra and aqua in the western North Pacific. Journal of Oceanography 63 (2), 267-280.

Howarth, M., Simpson, J., Sündermann, J., van Haren, H., 2002. Processes of Vertical Exchange in Shelf Seas (PROVESS). Journal of Sea Research 47 (3-4), $199-208$.

ICES, 2005. The Annual ICES Ocean Climate Status Summary 2004/2005. Tech. rep., ICES Cooperative Research Report, No. 275. 37 pp.

Judd, A., 2015. The significance of the 22/4b blow-out site methane emissions in the context of the North Sea. Journal of Marine and Petroleum Geology this issue.

Judd, A., Hovland, M., 2007. Seabed Fluid Flow. Cambridge University Press, New York. 
Judd, A., Hovland, M., Dimitrov, L., Garcia Gil, S., Jukes, V., 2002. The geological methane budget at continental margins and its influence on climate. Geofluids 2, 109-126.

Knight, P., Howarth, M., Rippeth, T., 2002. Inertial currents in the northern North Sea. Journal of Sea Research 47 (3-4), 269 - 284.

Leifer, I., Clark, J., Chen, R., 2000. Modifications of the local environment by natural marine hydrocarbon seeps. Geophysical Research Letters 27, 3711-3714. Leifer, I., Jeuthe, H., Gjøsund, S., Johansen, V., 2009. Engineered and natural marine seep, bubble-driven buoyancy flows. J. Phys. Oceanography 39, 30713090.

Leifer, I., Judd, A., 2015. The UK22/4b blowout 20 years on: Investigations of continuing methane emissions from sub-seabed to the atmosphere in a North Sea context. Journal of Marine and Petroleum Geology this issue.

Leifer, I., Luyendyk, B., Boles, J., Clark, J., 2006. Natural marine seepage blowout: Contribution to atmospheric methane. Global Biogeochemical Cycles 20. Leifer, I., Patro, R., 2002. The bubble mechanism for methane transport from the shallow sea bed to the surface: A review and sensitivity study. Continental Shelf Research 22, 2409-2428.

Leifer, I., Solomon, E., Coffin, R., Rehder, G., Linke, P., 2015. The fate of bubbles in a large, intense bubble plume for stratified and unstratified water: Numerical simulations of 22/4b expedition field data. Journal of Marine and Petroleum Geology this issue.

Linke, P., 2012. RV Celtic Eexplorer Eurofleets Cruise Report CE12010, ECO2@NorthSea. Tech. rep., GEOMAR, Helmholtz Zentrum für Ozeanforschung Kiel.

Luyten, P., Carniel, S., Umgiesser, G., 2002. Validation of turbulence closure parameterisations for stably stratified flows using the PROVESS turbulence measurements in the North Sea. Journal of Sea Research 47 (3-4), 239 - 267. Lwiza, K., Bowers, D., Simpson, J., 1991. Residual and tidal flow at a tidal mixing front in the North Sea. Continental Shelf Research 11 (11), 1379 - 1395.

Maas, L., van Haren, J., 1987. Observations on the vertical structure of tidal and inertial currents in the central North Sea. Journal of Marine Research 45 (2), 293-318.

Mackinnon, J. A., Gregg, M. C., 2005. Near-inertial waves on the New England Shelf: The role of evolving stratification, turbulent dissipation, and bottom drag. J. Phys. Oceanogr. 35 (12), 2408-2424.

Matthews, J., Fox, A., Prandle, D., 1993. Radar observation of an along-front jet and transverse flow convergence associated with a North Sea front. Continental Shelf Research 13 (1), 109 - 130.

McClimans, T. A., Johnson, D. R., Krosshavn, M., King, S. E., Carroll, J., Grenness, i., 2000. Transport processes in the Kara Sea. J. Geophys. Res. 105 (C6), 14121-14139.

Milgram, J., 1983. Mean flow in round bubble plumes. Journal Fluid Mechanics 133, 345-376.

Nakhle, C., 2008. Can the North Sea still save Europe? OPEC Energy Review 32, $123-138$.

Nauw, J., de Haas, H., 2013. A modelling intercomparison for the North Sea with a view to methane dispersion. Tech. rep., NIOZ.

Nauw, J., de Haas H., Rehder, G., 2015. A review of Oceanographic and Meteorological Controls on the Fate of North Sea Methane from a seabed source. Journal of Marine and Petroleum Geology this issue. 
Otto, L., Zimmerman, J., Furnes, G., Mork, M., Saetre, R., Becker, G., 1990. Review of the physical oceanography of the North Sea. Netherlands Journal of Sea Research 26 (2-4), 161 - 238.

Pawlowicz, R., Beardsley, B., Lentz, S., 2002. Classical tidal harmonic analysis including error estimates in MATLAB using T_TIDE. Computers and Geosciences 28, 929-937.

Pingree, R. D., Griffiths, D. K., 1978. Tidal fronts on the shelf seas around the British Isles. Journal of Geophysical Research: Oceans 83 (C9), 4615-4622.

Rehder, G., Keir, R. S., Suess, E., Pohlmann, T., 1998. The Multiple Sources and Patterns of Methane in North Sea Waters. Aquatic Geochemistry 4, 403-427. Rehder, G., Keir, R. S., Suess, E., Rhein, M., 1999. Methane in the northern Atlantic controlled by microbial oxidation and atmospheric history. Geophys. Res. Lett. 26 (5), 587-590.

Rehder, G., Kirby, S., Durham, W., Stern, L., Peltzer, E., Pinkston, J., Brewer, P., 2004. Dissolution rates of pure methane hydrate and carbon-dioxide hydrate in undersaturated seawater at 1000-m depth. Geochimica et Cosmochimica Acta 68, 285-292.

Rippeth, T. P., 2005. Mixing in seasonally stratified shelf seas: a shifting paradigm. Philosophical Transactions of the Royal Society A: Mathematical, Physical and Engineering Sciences 363 (1837), 2837-2854.

Schneider von Deimling, J., Brockhoff, J., Greinert, J., 2007. Flare imaging with multibeam sonar systems: data processing for seep bubble detection.

Geochemistry, Geophysics, Geosystems 8 (6), Q06004.

Schneider von Deimling, J., Linke, P., Schmidt, M., G., R., 2015. Ongoing methane discharge at well site 22/4b (North Sea) and discovery of a spiral vortex bubble plume motion. Journal of Marine and Petroleum Geology this issue. Schneider von Deimling, J., Rehder, G., Greinert, J., McGinnnis, D., Boetius, A., Linke, P., 2011. Quantification of seep-related methane gas emissions at Tommeliten, North Sea. Continental Shelf Research 31 (7-8), $867-878$. Scranton, M. I., McShane, K., 1991. Methane fluxes in the southern North Sea: the role of European rivers. Continental Shelf Research 11 (1), 37-52.

Sem, T., Ellerman, D., 1999. North Sea reserve appreciation, production and depletion, Working Paper. Massachusetts Institute of Technology, Cambridge. Simpson, J. H., Pingree, R. D., 1978. Shallow sea fronts produced by tidal stirring. In: Bowman, M., Esaias, W. (Eds.), Oceanic Fronts in Coastal Processes. Springer Berlin Heidelberg, pp. 29-42.

Solomon, E., Kastner, M., MacDonald, I., Leifer, I., 2009. Considerable methane fluxes to the atmosphere from hydrocarbon seeps in the Gulf of Mexico. Nature Geoscience 2, 561-565.

Souza, A., Simpson, J., 1996. The modification of tidal ellipses by stratification in the Rhine ROFI. Continental Shelf Research 16 (8), 997 - 1007.

Teledyne RD Instruments, 2010. ADCP Coordinate Transformation: Formulas and Calculations. San Diego, California.

Turrell, W., Henderson, E., Slesser, G., 1990. Residual transport within the Fair Isle Current observed during the Autumn Circulation Experiment (ACE). Continental Shelf Research 10 (6), 521 - 543.

Turrell, W., Henderson, E., Slesser, G., Payne, R., Adams, R., 1992. Seasonal changes in the circulation of the northern North Sea. Continental Shelf Research $12(2-3), 257-286$.

Turrell, W. R., Slesser, G., Payne, R., Adams, R. D., Gillibrand, P. A., 1996. Hydrography of the East Shetland Basin in relation to decadal North Sea variability. ICES Journal of Marine Science: Journal du Conseil 53 (6), 899-916. 
van Aken, H. M., van Heijst, G. J. F., Maas, L. R. M., 1987. Observations of fronts in the North Sea. Journal of Marine Research 45 (3), 579-600.

van Haren, H., 2000. Properties of vertical current shear across stratification in the North Sea. Journal of Marine Research 58 (3), 465-491.

van Haren, H., Maas, L., Zimmerman, J. T. F., Ridderinkhof, H., Malschaert, H., 1999. Strong inertial currents and marginal internal wave stability in the central North Sea. Geophysical Research Letters 26 (19), 2993-2996.

Vielstädte, L., Karstens, J., Haeckel, M., Schmidt, M., Linke, P., Reimann, S., Liebetrau, V., McGinnis, D., Wallmann, K., 2015. Quantification of methane emissions at abandoned gas wells in the Central North Sea. Journal of Marine and Petroleum Geology this issue.

Wüest, A., Brooks, N., Imbolden, D., 1992. Bubble plume modeling for lake restoration. Water Resource Research 28, 3235-3250.

Wiggins, S. M., Leifer, I., Linke, P., Hildebrand, J. A., 2015. Long-term acoustic monitoring at North Sea well site 22/4b. Journal of Marine and Petroleum Geology this issue.

Wilson, D., Leifer, I., Maillard, E., 2015. Megaplume bubble process visualization by 3D multibeam sonar mapping. Journal of Marine and Petroleum Geology this issue.

Woods, A. W., 2010. Turbulent plumes in nature. Annual Review of Fluid Mechanics 42 (1), 391-412. 
Figures
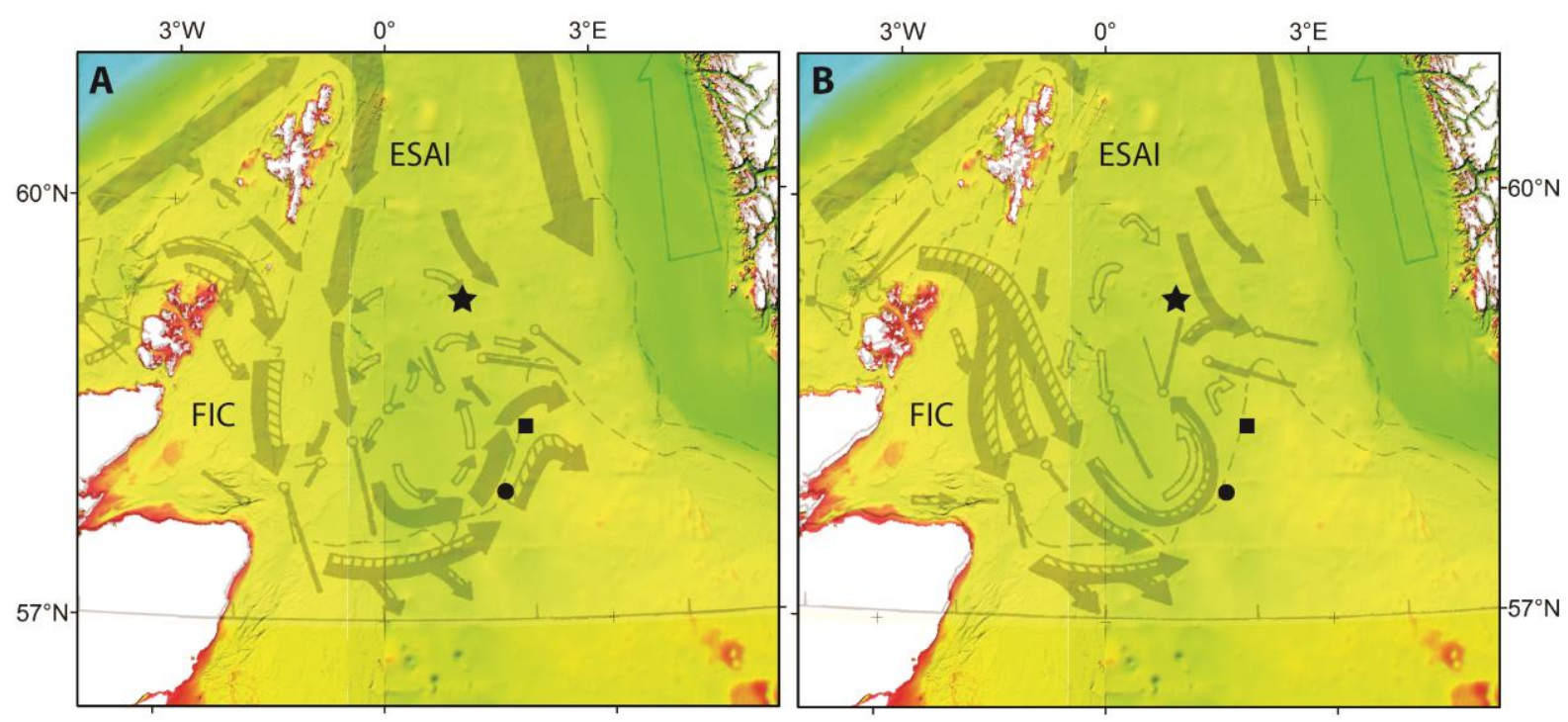

- $22 / 4 b$

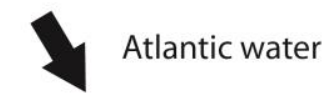

- Sleipner

^ PROVESS

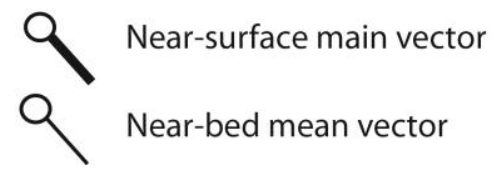

Figure 1: Map showing the key features of the topography of the North Sea and the adjacent oceanic areas in relation to the proposed seasonal circulation pattern in the northern North Sea and northwest of Scotland and the locations of the 22/4b Site (bullet), the PROVESS site (star), and the Sleipner Platform (filled square); A. stratified summer situation, B. mixed winter situation; ESAI - East Scotland Atlantic Inflow; FIC - Fair Isle Current (modified from Turrell et al., 1992). 

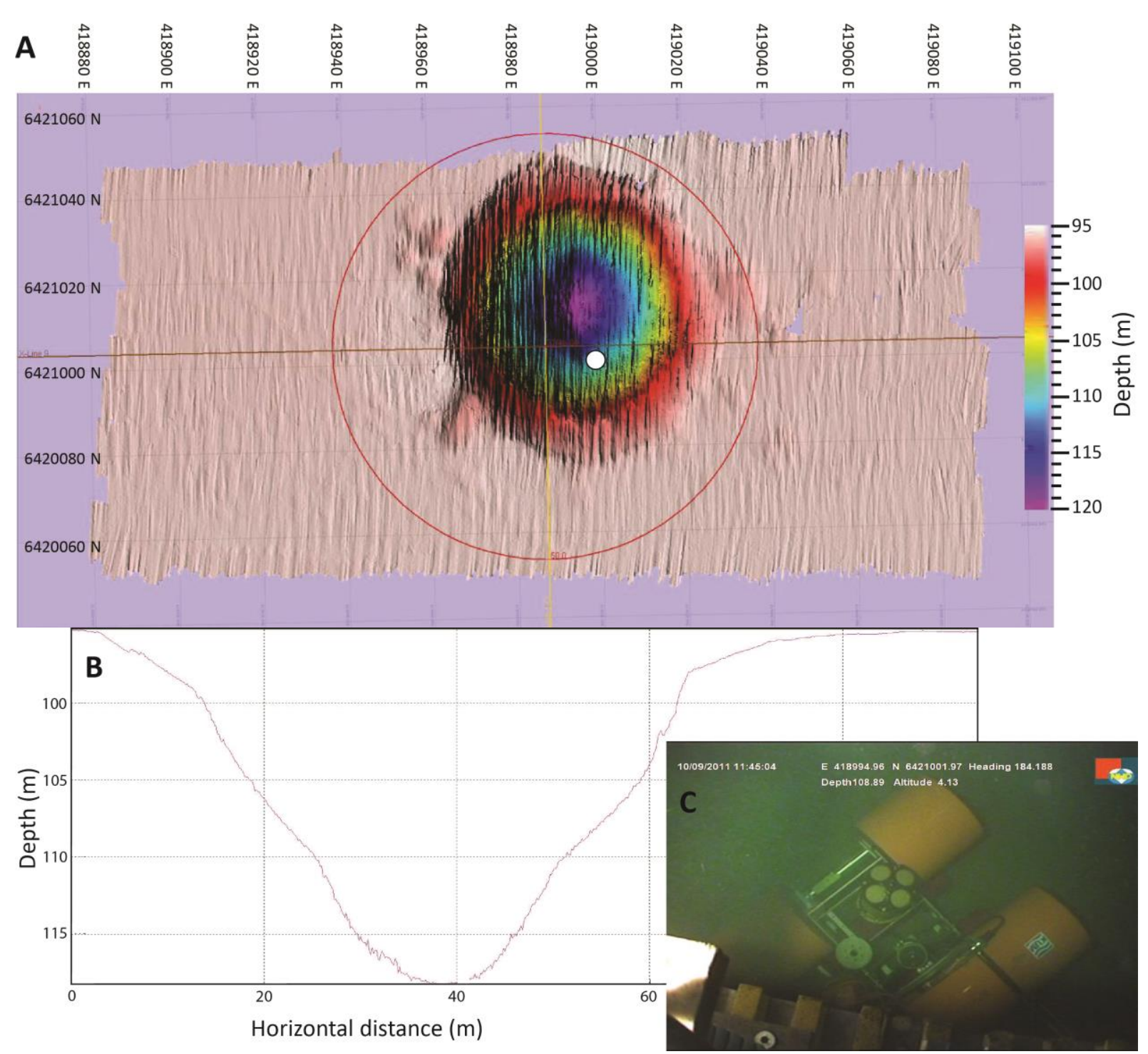

Figure 2: A. Overall 22/4b-4 crater topography, and B. Profile through 22/4b-4 crater including the approximate location of the lander on a ledge, $\mathrm{C}$. Image of the lander on the sea floor. 

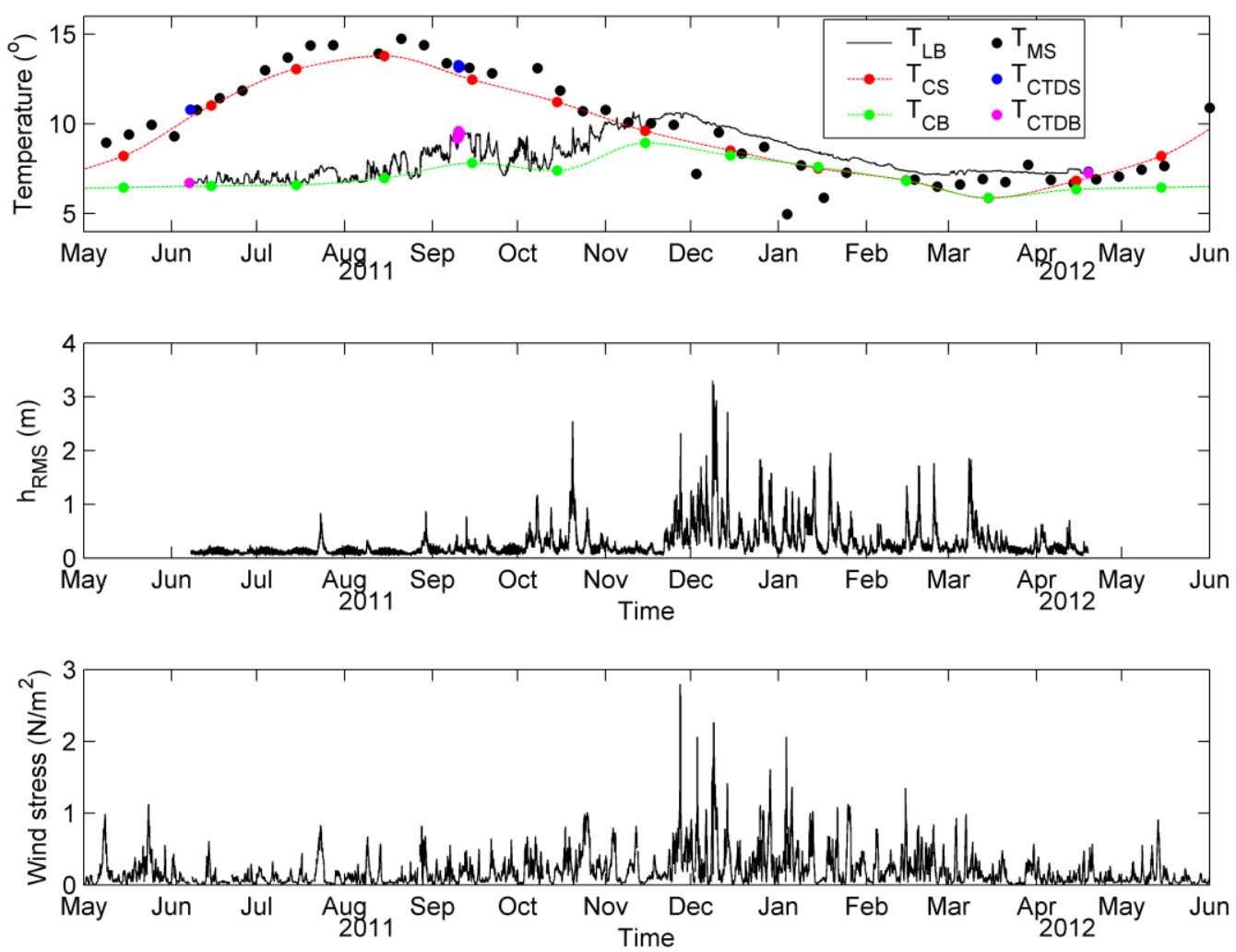

Figure 3: Top: Time-series of the temperature $\left({ }^{\circ} \mathrm{C}\right.$ ) on the landers (drawn), $T_{L B}$. Black dots represent the Sea Surface Temperatures (SST) at the location of the landers based on the 8 day composites of the MODIS Level 3 SST maps, TMS. Blue (magenta) dots represent surface (bottom) temperatures derived from CTD casts, $T_{C T D S}$ (surface) and $T_{C T D B}$ (bottom). Red (green) dots connected with dashed lines are the climatological values for the temperature at the surface, $T_{C S}$ (near the bottom, $T_{C B}$ ) at the location of the landers derived from the climatological values (Berx and Hughes, 2009). Middle: RMS wave height (m). Bottom: Wind stress $\left(\mathrm{Nm}^{-2}\right)$ using wind speeds at the nearby Sleipner platform at $58^{\circ} 22^{\prime} \mathrm{N}$ and $1^{\circ} 55^{\prime} \mathrm{E}$ (Figure 1 ). 


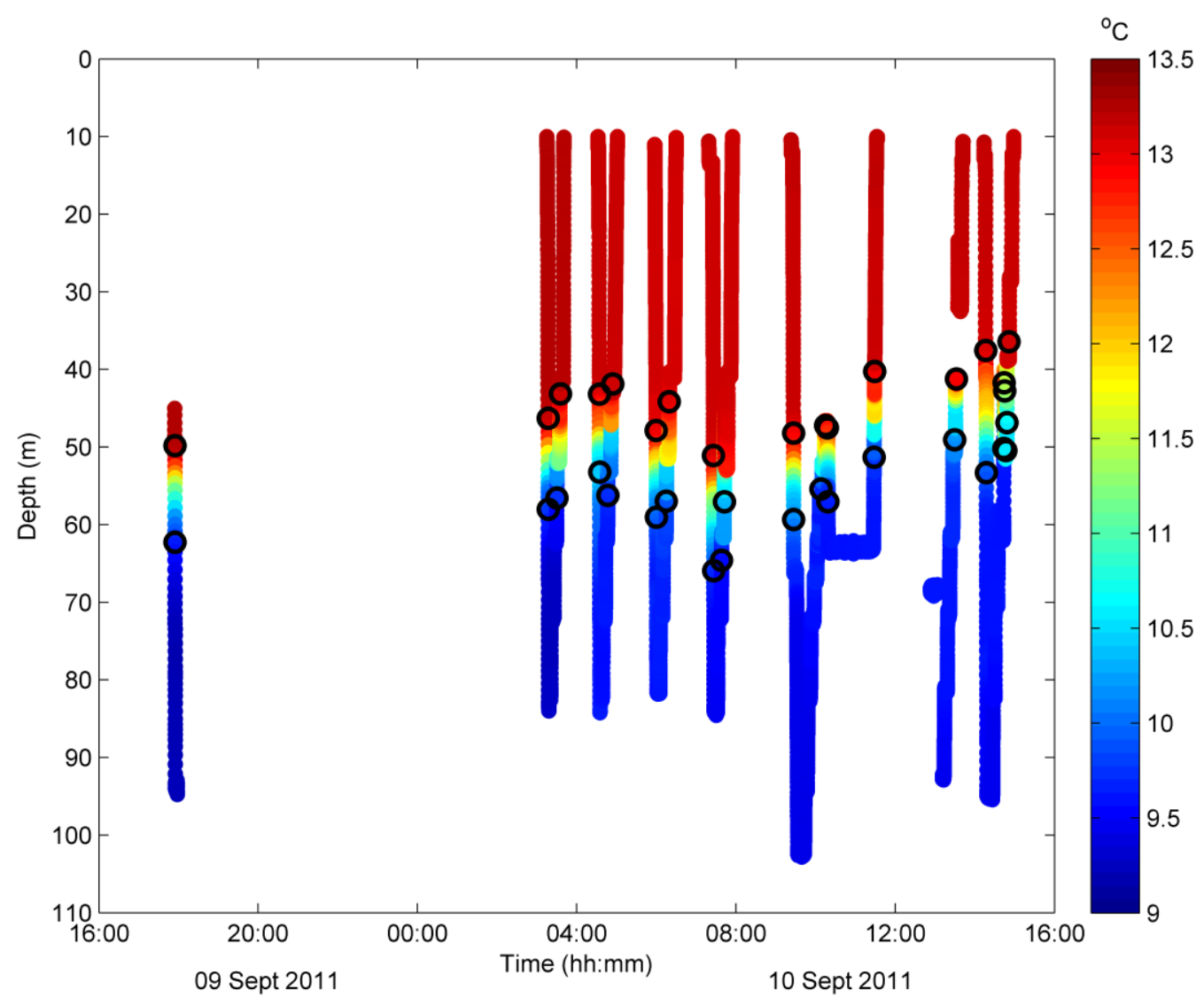

Figure 4: Vertical CTD profiles with time on the horizontal and depth on the vertical axis. Colors indicate the temperature $\left({ }^{\circ} \mathrm{C}\right)$ and the black circles indicate the top and the base of the thermocline, MLD and BTH, respectively. 

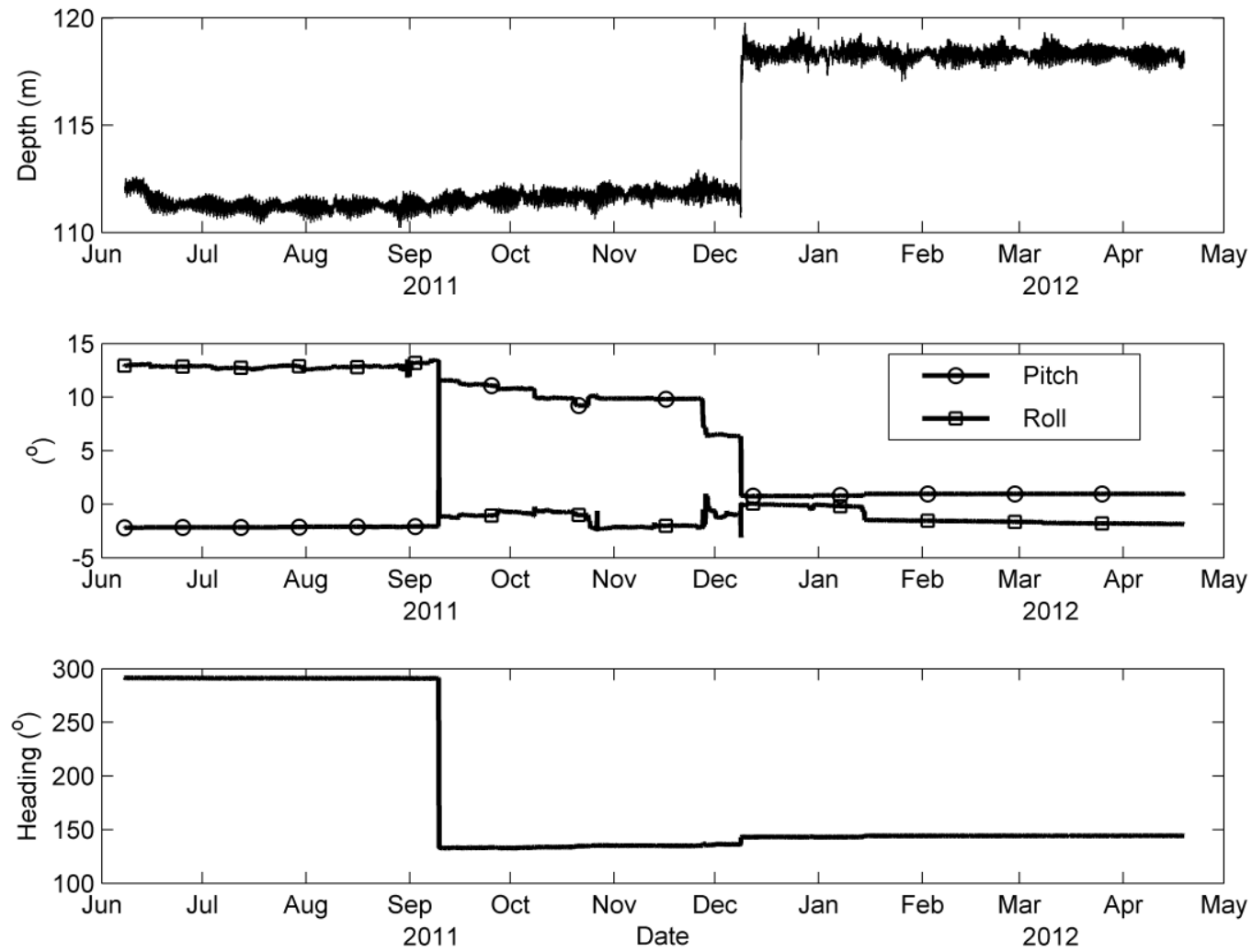

Figure 5: Local lander water depth $(\mathrm{m})$, Pitch $\left({ }^{\circ}\right.$, circles) and Roll ( ${ }^{\circ}$, squares) and heading $\left({ }^{\circ}\right)$ as a function of date for both landers. 

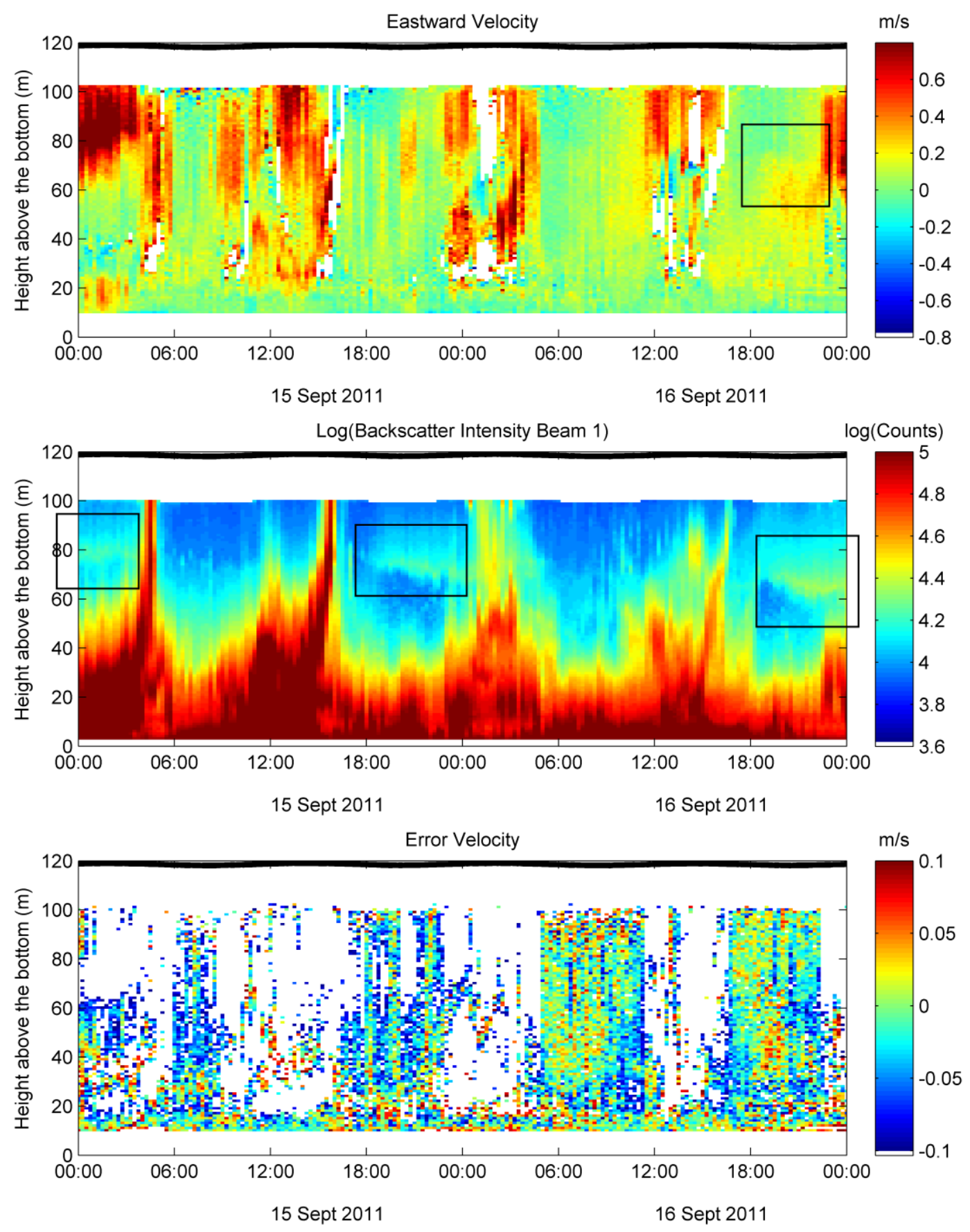

Figure 6: Top: Eastward velocity (m/s); middle: echo intensity beam $1(\mathrm{~dB})$ and bottom: error velocity (m/s) for the period between 15 and 17 September 2011. Data with an absolute error velocity of more than $\left|v_{\text {err }}\right|>0.1$ and $v_{\text {err }}=0$ (3-beam solutions) are intentionally left blank in the bottom panel. Boxes are referred to in the text. 

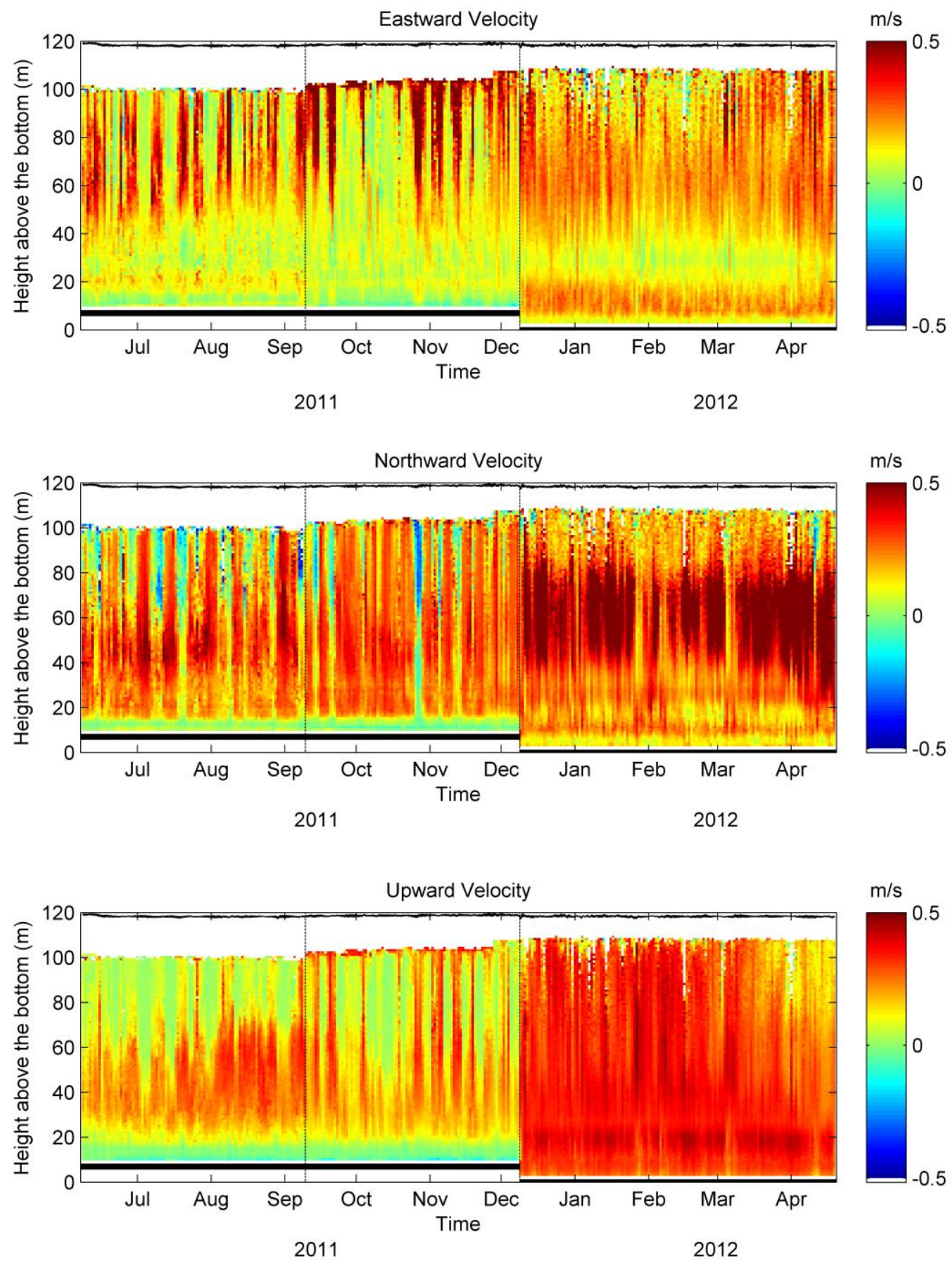

Figure 7: Daily mean eastward, northward, and upward components of the velocities $(\mathrm{m} / \mathrm{s})$. The lower black line in the figures represents the location of the ADCP and the black line at the top indicates the total depth $(\mathrm{m})$. Erroneous data are intentionally left blank. The vertical dashed lines are drawn on 9 September 15:00 UTC and 8 December 20:15 UTC, 2011. 

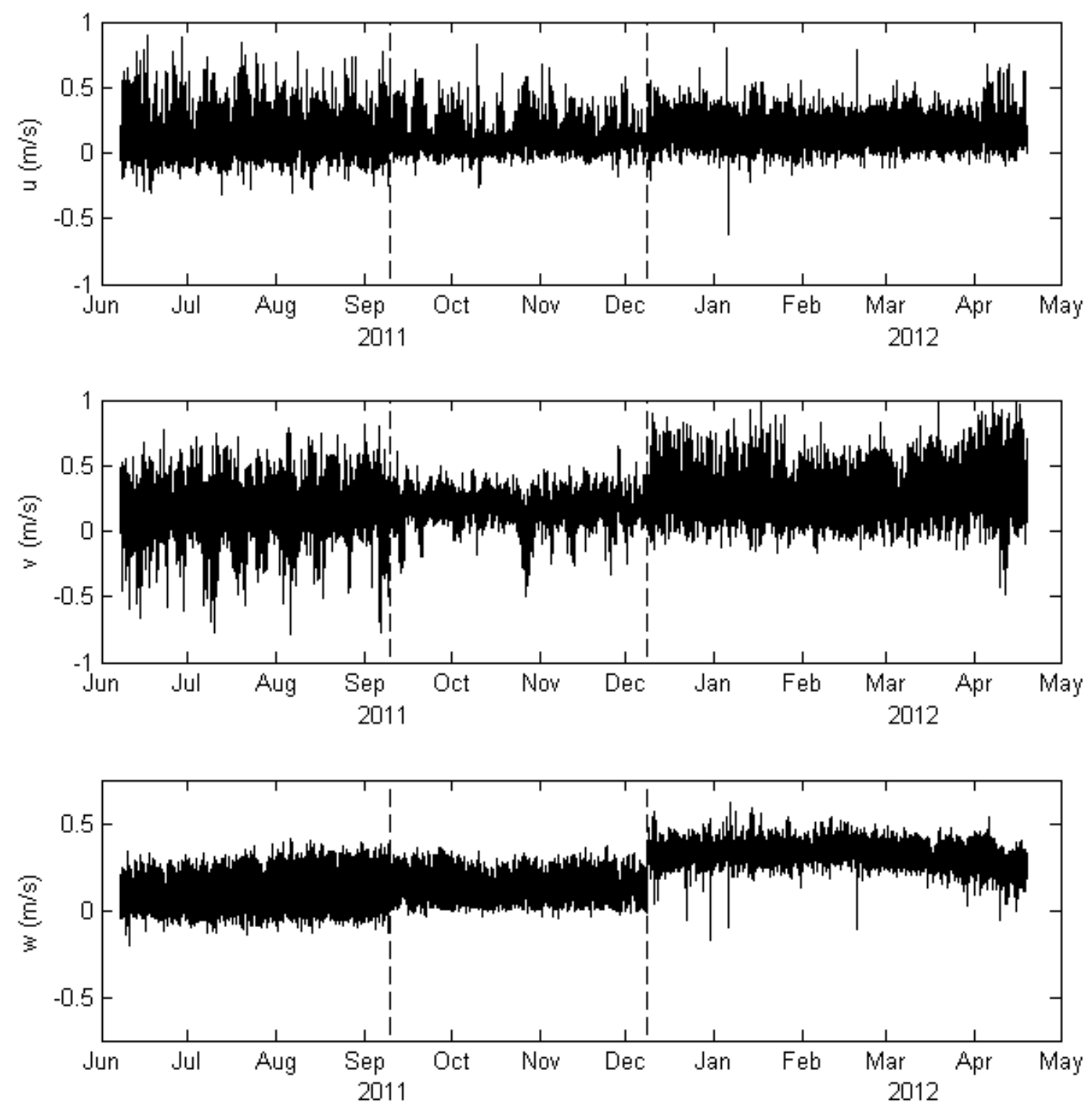

Figure 8: From top to bottom: time-series of the depth-averaged eastward, northward, and upward velocities $(\mathrm{m} / \mathrm{s})$. 

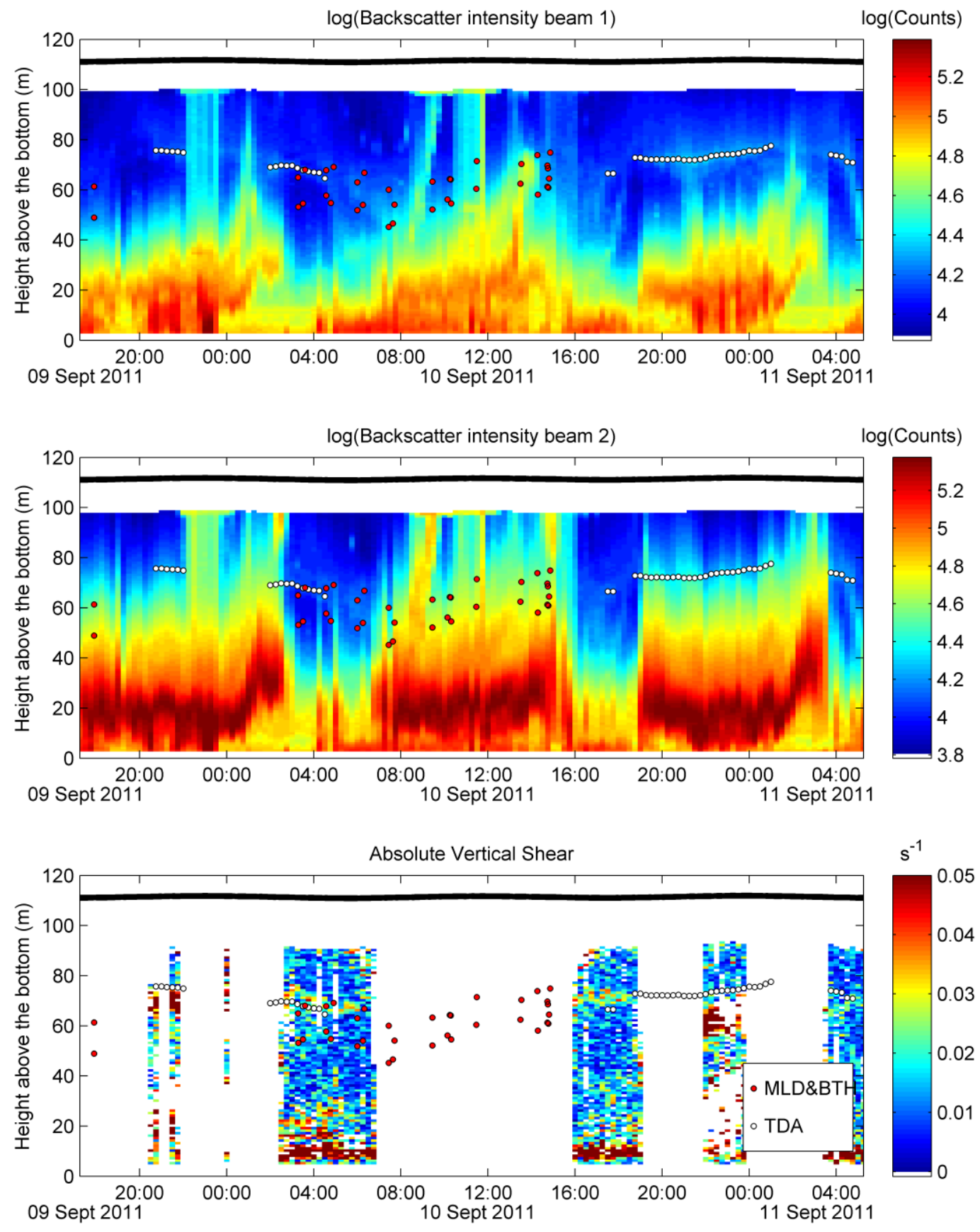

Figure 9: Logarithm of backscatter intensity, I, for beam 1 (top) and beam 2 (middle) and absolute value of the vertical shear (bottom) for 9 Sept 17:15 to 11 Sept $5: 15$. White dots mark the location of the height of the thermocline above seafloor using the thermocline detection algorithm and MLD and BTH are marked as red dots derived from the analysis of the CTD profiles as shown in Figure 4. 


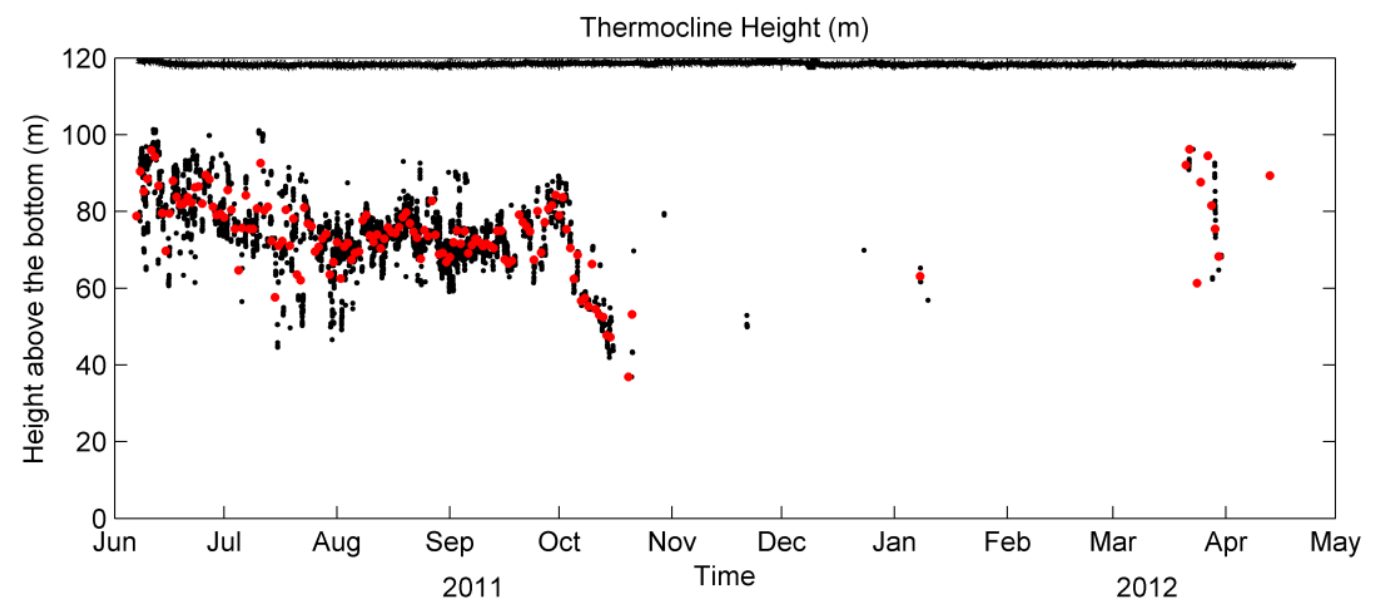

Figure 10: Height of the base of the thermocline, BTH. Black dots indicate the local mean maximum in the backscatter intensity averaged over the four different beams. The red dots represent the daily mean values, if more than 10 estimates were available for that particular day. 

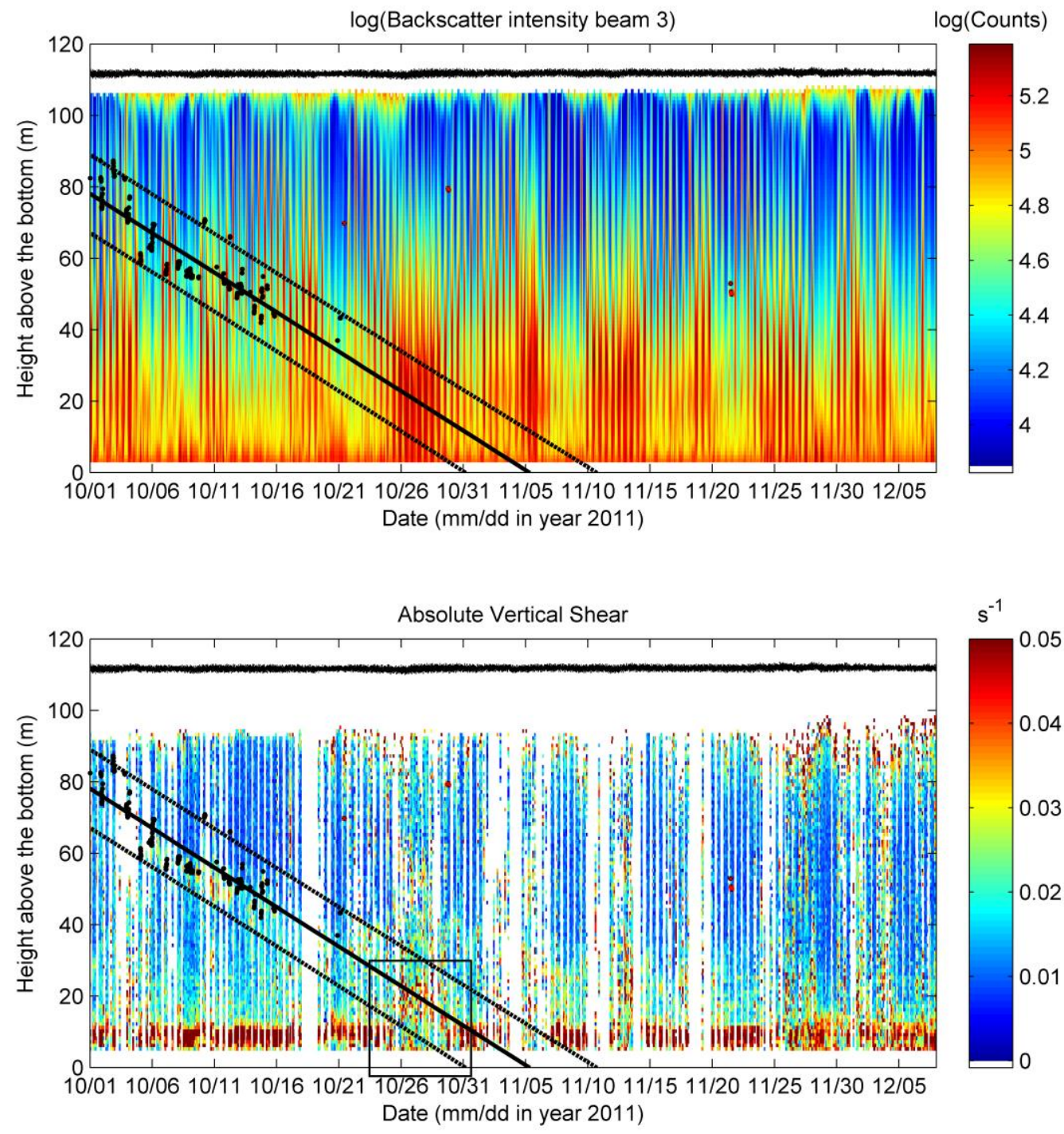

Figure 11: Top: Log (backscatter intensity of beam 3) and locations of the height of the base of the thermocline, BTH (black dots); bottom: absolute vertical shear and BTH. Outliers are marked as red dots and not taken into account in the linear regression. Drawn line is the linear regression through the black dots and the dashed lines represent the $95 \%$ prediction intervals in which the points higher than $60 \mathrm{~m}$ above the seafloor that occurred after 21 October were marked as outliers. The black box is referred to in the text. 

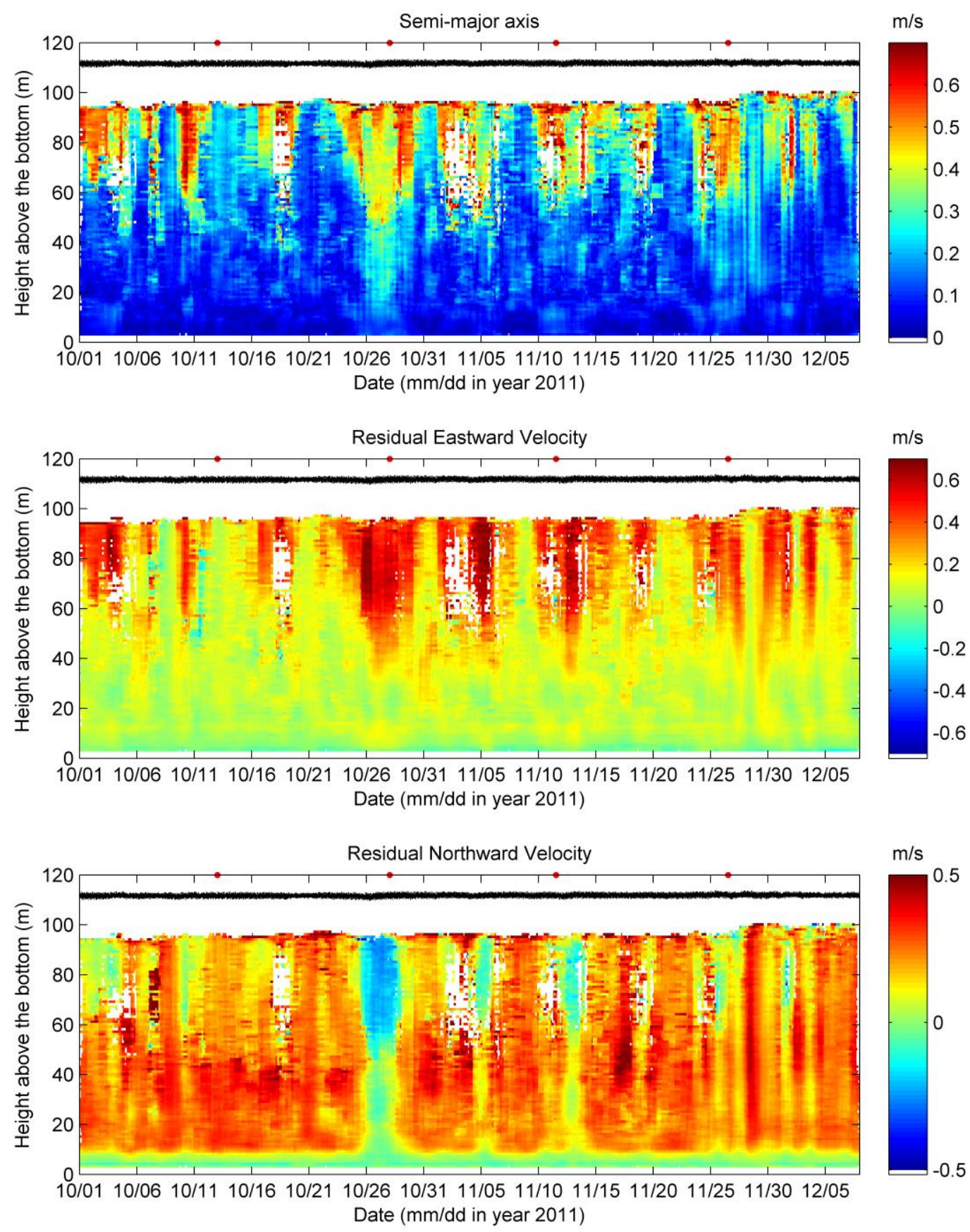

Figure 12: Semi-major axis or maximum tidal speed (top), residual eastward (middle) and northward (bottom) current $(\mathrm{m} / \mathrm{s}$ ) from a running LSHA with a window length of 1 day and based on the M2 tidal constituent. 

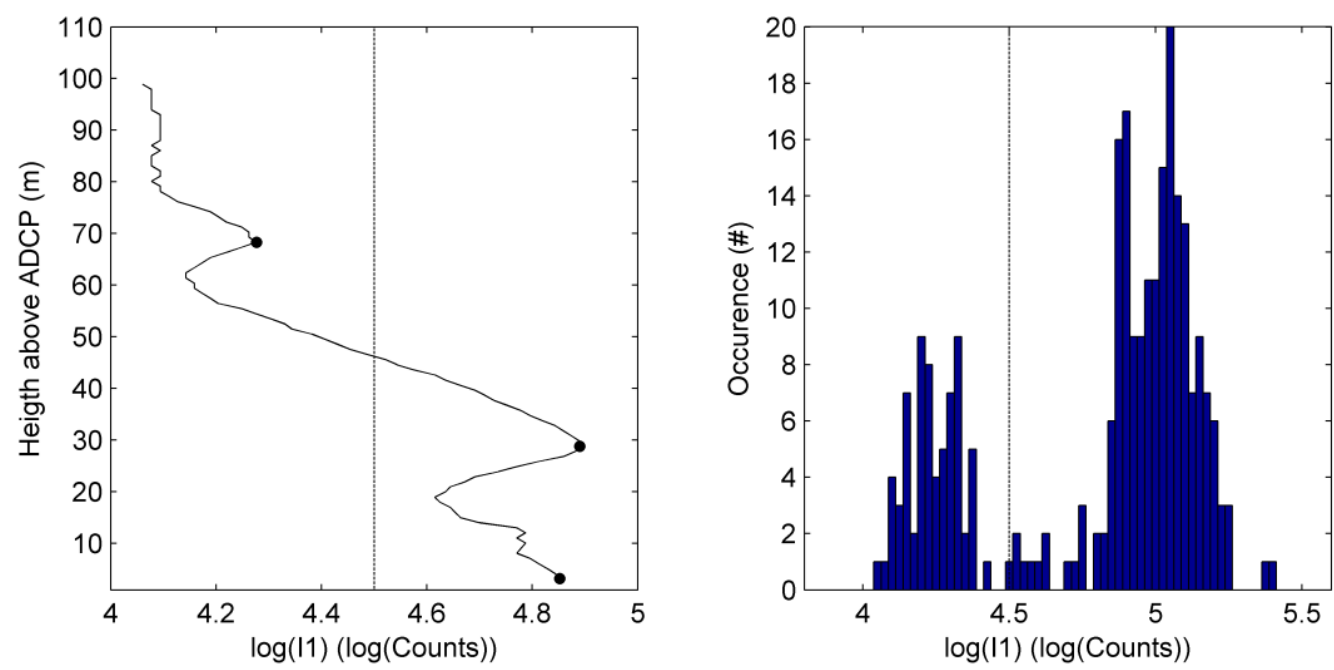

Figure A- 1: Left: Typical vertical profile of the logarithm of the backscatter intensity. Local maxima are indicated with black dots. Right: Histogram of the values of the logarithm of the backscatter intensity of beam 1 obtained between 9 September 2011, 17:15 UTC and 11 September 2011, 5:15 UTC. In both panels: The detection threshold is indicated by the dashed line.

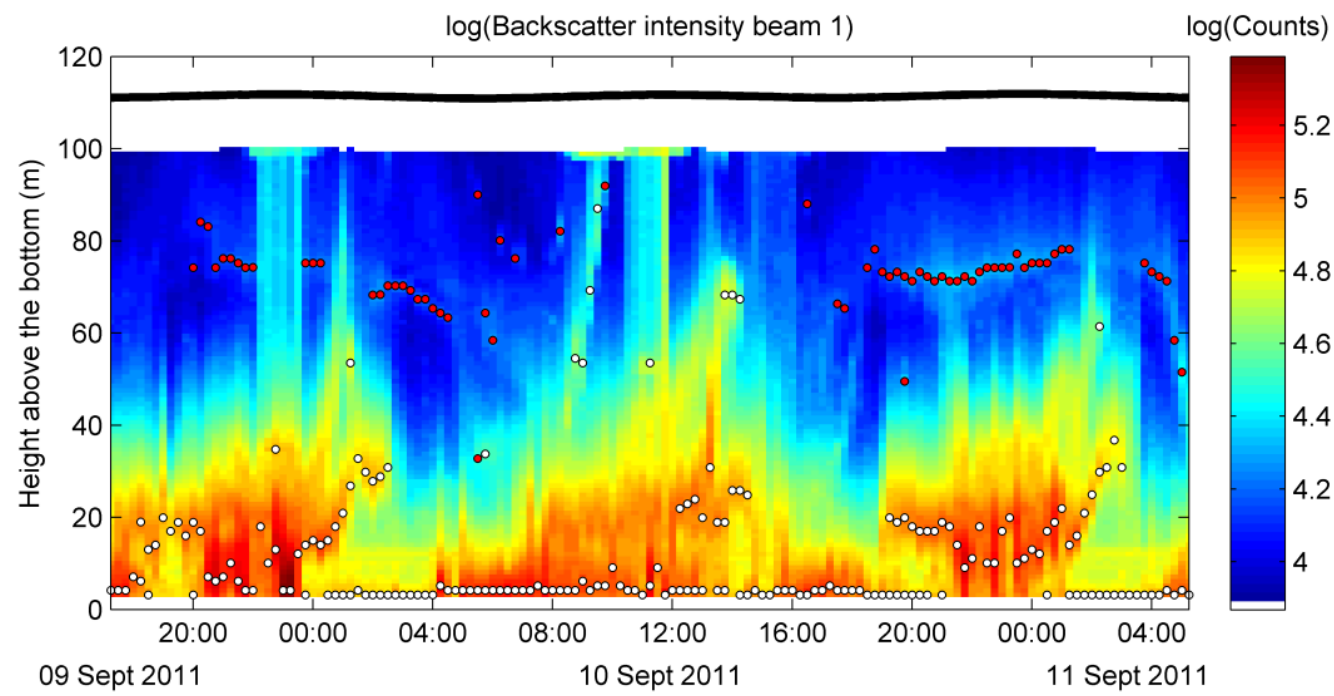

Figure A- 2: Logarithm of the backscatter intensity of beam 1 (colors background) and local maxima, which exceed values above and below by at least 1.1 Counts. Red dots indicate local maxima having a maximum lower than the threshold value of 4.5 and white dots mark local maxima that exceed the threshold value and are removed from the analysis, because they are clearly not related to the MLD or BTH. 


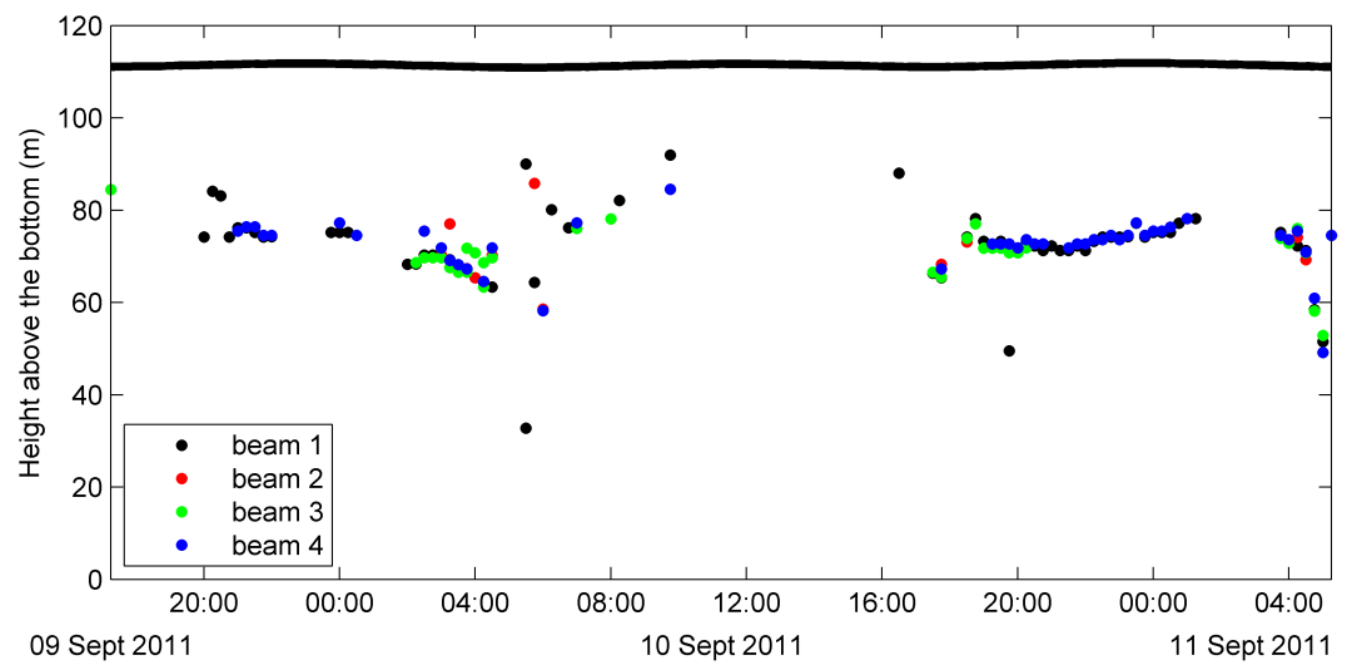

Figure A- 3: MLD determined with peak detection algorithm for beam 1 (black dots), beam 2 (red dots), beam 3 (green dots) and beam 4 (blue dots).
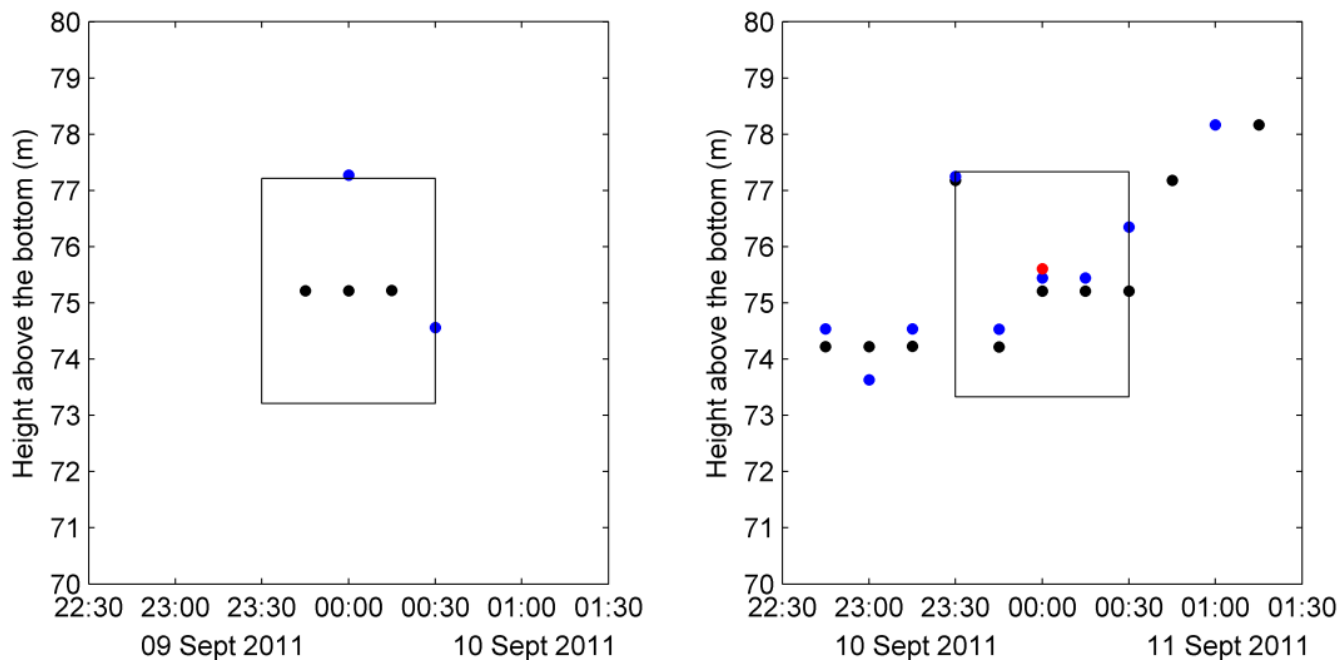

Figure A- 4: Applying the running window median filter with a window length of 1 hour and a range of $\pm 2 \mathrm{~m}$ around the median value. Left: the box with dimensions of 1 hour around midnight and $\pm 2 \mathrm{~m}$ around the median value of all values within that hour marks the top blue dot as an outlier, therefore only four estimates fulfill the criterion, where five is the minimum threshold and the MLD is set to $\mathrm{NaN}$ at midnight between 9 and 10 September. Right: the box with dimensions of 1 hour around midnight and $\pm 2 \mathrm{~m}$ around the median value of all values contains 10 estimates of the MLD; the mean value of these estimates (red dot) is the resulting MLD at midnight between 10 and 11 September. 


\section{Tables}

Table 1: Accuracy, stability and resolution of the instruments

\begin{tabular}{|l|l|l|l|}
\hline Sensor & Initial accuracy & Typical stability & Resolution \\
\hline Conductivity & $0.0005 \mathrm{~S} / \mathrm{m}$ & $\begin{array}{l}0.00003 \\
\mathrm{~S} / \mathrm{m} / \mathrm{month}\end{array}$ & $0.00005 \mathrm{~S} / \mathrm{m}$ \\
\hline Temperature & $0.0005 \mathrm{~S} / \mathrm{m}$ & $0.0002^{\circ} \mathrm{C}$ & $0.0001^{\circ} \mathrm{C}$ \\
\hline $\begin{array}{l}\text { Pressure (Quartz, } \\
10,000 \mathrm{psi})\end{array}$ & $\begin{array}{l}0.02 \% \text { of full scale } \\
\text { range }\end{array}$ & $\begin{array}{l}0.025 \% \text { of full } \\
\text { scale range/year }\end{array}$ & $\begin{array}{l}0.0006 \% \text { of full } \\
\text { scale range for } 1 \\
\text { sec integration }\end{array}$ \\
\hline
\end{tabular}

Table 2: Settings of the ADCPs on Lander-1 and Lander-2.

\begin{tabular}{|l|l|l|}
\hline & Lander-1 & Lander-2 \\
\hline Deployment & 07-Jun-2011 20:00:00 & 09-Sep-2011 17:15:00 \\
\hline Recovery & $09-$ Sep-2011 13:20:00 & $19-$ Apr-2012 04:00:00 \\
\hline Number of bins & 109 & 110 \\
\hline Time per ensemble & 10 minutes & 15 minutes \\
\hline Pings per ensemble & 70 & 50 \\
\hline Time per ping & 00.57 seconds & 18.00 seconds \\
\hline
\end{tabular}

Table 3: Residuals (subscript 0) and amplitudes (subscript M2) of the LSHA applied to the depth-averaged velocities in eastward, northward and upward velocities, $u, v, w$, respectively.

\begin{tabular}{|l|l|l|l|l|}
\hline & Entire time-series & Period 1 & Period 2 & Period3 \\
\hline$u_{0}$ & 0.23 & 0.11 & 0.11 & 0.16 \\
\hline$v_{0}$ & 0.22 & 0.16 & 0.19 & 0.28 \\
\hline$w_{0}$ & 0.20 & 0.10 & 0.13 & 0.33 \\
\hline$u_{M 2}$ & 0.10 & 0.04 & 0.05 & 0.02 \\
\hline$v_{M 2}$ & 0.05 & 0.07 & 0.07 & 0.04 \\
\hline$w_{M 2}$ & 0.01 & 0.02 & 0.04 & 0.01 \\
\hline
\end{tabular}

Table B-1: Values of the parameters in the equations in Appendix B for determining the $95 \%$ prediction interval.

\begin{tabular}{|l|l|l|}
\hline Desciption & Name & Value \\
\hline Slope & $\mathrm{m}$ & -2.2 \\
\hline Intercept & $\mathrm{b}$ & $7.8 \cdot 10^{1}$ \\
\hline Number of observations & $\mathrm{N}$ & 258 \\
\hline $\begin{array}{l}\text { Standard Error in the } \\
\text { Estimate }\end{array}$ & $\mathrm{S}_{\mathrm{xy}}$ & 5.5 \\
\hline Average $\mathrm{x}$ & $\bar{x}$ & 7.6 \\
\hline Sum of Deviation squared & $\mathrm{S}_{\mathrm{xx}}$ & $5.4 \cdot 10^{3}$ \\
\hline t statistic & $\mathrm{t}(\mathrm{a}, \mathrm{df})$ & 1.97 \\
\hline
\end{tabular}

